\title{
Study on the Effects of Sars-Cov-2 Infection on the Hematological and Biochemical Parameters and Clinicopathological Correlation in the Evolution of Covid-19
}

\author{
Rakesh Holla A ${ }^{1 *}$, Amit Sharma ${ }^{2}$ and Naveen Chawla ${ }^{3}$ \\ ${ }^{1}$ Department of Pathology, 160 Military Hospital Silchar, Assam, India \\ ${ }^{2}$ Consultant Pathologist, Sampurna Sodani Diagnostics Pvt. Ltd, Indore, Madhya \\ Pradesh, India
}

${ }^{3}$ INHS Asvini Colaba, Mumbai, Maharashtra, India

*Corresponding Author: Rakesh Holla A, Department of Pathology, 160 Military

Hospital Silchar, Assam, India.
Received: July 25, 2021

Published: September 18, 2021

(C) All rights are reserved by Rakesh Holla A. et al.

\section{Abstract}

The pandemic Covid-19 is caused by a single stranded RNA virus, SARS-CoV2 (Severe Acute Respiratory Syndrome Coronavirus 2). SARS CoV2 is one of the coronaviruses, primarily a respiratory infection with a significant impact on hematopoietic system and hemostasis. However, it is now learnt that Covid-19 also known to cause multisystem disorder with Kawasaki disease like fever in children. SARS-CoV-2 spreads via respiratory droplet and surface to human transmission via fomites where the virus can enter the mucus membrane of eyes, nose and mouth. Though asymptomatic/mild cases account for large number of cases, it is also postulated that the viral load is higher in pre-symptomatic cases compared to those with severe disease thereby making them most important overlooked viral shedders contributing to highly contagiousness of the infection. Therefore, early diagnosis of Covid-19 is critical for prevention and control of this pandemic and the clinical characteristics alone cannot define the diagnosis of Covid-19, especially for pre-symptomatic and asymptomatic patients.

Nuclei acid detection based approaches have become a rapid and reliable technology for detection of virus, and amongst them real time Reverse Transcriptase-Polymerase Chain Reaction (RT-PCR) is considered as the 'Gold standard' for the detection SARS-CoV-2. The real time RT-PCR has adequate sensitivity and high specificity in the diagnosis Covid-19 particularly the early infection. However, the important drawback with RT-PCR application is the risk of eliciting false-negative results which in the current pandemic can be perilous and a major impediment in the containment of outbreaks. It is reported that many 'suspected' cases with typical clinical characteristics of Covid-19 and diagnostic computed tomography (CT) images were not diagnosed with RT-PCR [15]. Thus, a negative result does not exclude the possibility of Covid-19 infection entirely and therefore should not be used as the only criterion in the management of Covid-19 cases.

We carried out a study to assess the effects of SARS-CoV-2 on the hematopoietic and biochemical profile which might provide for an alternative mechanism to diagnose Covid-19, particularly in hospital settings when patients are being evaluated in the Non-Covid zone of the hospital or in resource constraint settings where Nucleic Acid based tests are not readily available for the diagnosis of Covid-19. The study was carried out on individuals who were serving in an organization that generates physically fit and mentally robust individuals, thereby weeding out affection of any other confounding factors such as obesity, cardiovascular disease and other co-morbidities on the evolution of the disease. A total of 250 Covid-19 positive patients were evaluated hematologically and biochemically between June 2020 and October 2020.

The Complete Blood Count (CBC) of the Covid-19 patients revealed normal Total Leukocyte Count (TLC) in more than $90 \%$ of patients, Leukocytopenia in less than $5 \%$ of patients, Leukocytosis in about $05 \%$ of cases and Thrombocytopenia in $5 \%$ of cases. It is pertinent to note that majority of the patients, particularly those presenting early in the course of the disease as pre-symptomatic illness, initially presented with Relative Lymphocytosis on days 2 to 3 post sampling that yielded a positive result for Covid-19. The 
Peripheral Blood Smear (PBS) confirmed the initial Relative Lymphocytosis with presence of characteristic Covicytes (Activated Lymphocytes) and Acquired Pseudo Pelger Huet Anomaly (APHA). With recovery, Covicytes gradually decrease in number but there is persistence of occasional covicytes which were observed in most patients who were assessed hematologically prior to discharge after being declared Covid-19 by RT-PCR testing. While the proportion of covicytes reduced as the patients recovered with improvement in symptomatology and waning viral loads, the Acquired Pseudo Pelger Huet anomaly in the neutrophils persisted for protracted periods of time and was appreciated in peripheral blood smear examination carried out when these Covid-19 recovered patients returned for blood evaluation for some other ailment weeks later

The proposed approach also provides an alternative cheap and reliable Infection Prevention and Control mechanism in hospital settings for detecting Covid-19 cases amongst in-patients who were missed either during clinical assessment, if done cursorily or as RT-PCR false-negative cases. It will also enable efficient contact tracing, in the event of such patients being confirmed as Covid-19 positive cases. Correlation between Covicytes, APHA and inflammation associated markers such as CRP, LDH and Neutrophil to Lymphocyte Ratio (NLR) were also drawn. We analyzed that there is a linear correlation between lymphocyte decline, raised NLR, heightened inflammation markers and severity of infection.

Keywords: Pandemic; SARS-CoV-2 (Severe Acute Respiratory Syndrome Coronavirus 2); Covid-19; hematological assessment, hematological profile, Biochemical profile, Inflammatory markers, Relative lymphocytosis, Peripheral blood smear, Activated Lymphocytes, atypical lymphocytes, Covicytes, Acquired Pseudo Pelger Huet Anomaly (APHA), Quarantine, Isolation

\section{Introduction}

The pandemic Covid-19 is caused by a single stranded RNA virus, which was initially called at the outset as Novel Coronavirus 2019 and later rechristened by WHO with the now official name SARS-CoV2 (Severe Acute Respiratory Syndrome Coronavirus 2) as it bears almost $80 \%$ resemblance in its genome with another coronavirus SARS [11]. SARS CoV2 is one of the coronaviruses, of which 04 cause mild flu like illness while the remaining two being SARS (Severe Acute Respiratory Syndrome) virus and MERS (Middle East Respiratory Syndrome) virus. The genomic sequence data has revealed that the SARS-CoV-2 is a member of Betacoronavirus and belongs to the subgenus Sarbecovirus which also includes SARSCoV while MERS-CoV belongs to a separate subgenus, Merbecovirus $[10,11]$. SARS-CoV2 infection causes coronavirus disease 2019 (Covid-19), primarily a respiratory infection with a significant impact on hematopoietic system and hemostasis leading to several Cardiovascular complications. However, it is now learnt that Covid-19 also known to cause multisystem disorder with Kawasaki disease like fever in children.

With the origin as an epidemic pneumonia in Wuhan in $\mathrm{Hu}-$ bei Province of China in Dec 2019, the Covid-19 spread rapidly throughout the world, evolving into a global pandemic. Epidemiological data suggests that SARS-CoV-2 had spread widely from the city of Wuhan in China after its Zoonotic transmission origi- nating from bats via the Malayan pangolins [12,13]. Covid-19 was declared as Public Health Emergency of International Concern (PHEIC) on 30 Jan 2020 and with ensuing rapid global spread due to well established air connectivity with various countries across the continents. SARS-CoV2 epidemic was declared as a pandemic in Mar 2020. Covid-19 has a very large pattern of varied manifestations from respiratory symptoms to fever and other non-specific symptoms including headache, malaise, bodyache, nausea, vomiting, diarrhoea, red eye, loss of smell and taste, loss of appetite, myalgia, cardiac rhythm problems, cardiac failure, confusion, headache, seizures, Guillain Barre syndrome, fainting spells, deranged sugar profile and others. It has already affected more than $10 \%$ of the population worldwide. In India, with more than 11 lakh cases, more than $90 \%$ of affected people become symptomatic within 2 weeks of infection.

It spreads via human to human transmission via respiratory droplet and surface to human transmission via fomites where the virus can enter the mucus membrane of eyes, nose and mouth. Global sequence and epidemiological data reveal that the SARSCoV2 has spread rapidly to all parts of the globe by its ability to use the human ACE2 receptor for cellular entry [9]. The attachment of SARS-CoV2 to the target cell is initiated by the interactions between the spike glycoprotein (S) and its cognate receptor, Angiotensin Converting Enzyme 2 (ACE2) receptors, which are found 
Study on the Effects of Sars-Cov-2 Infection on the Hematological and Biochemical Parameters and Clinicopathological Correlation in the Evolution of Covid-19

widely distributed throughout human body including lungs, heart, muscle, kidney, blood vessels, CNS, liver and others [14]. Following the receptor engagement, SARS-CoV2 is processed by a plasma membrane associated type II transmembrane serine protease TMPRSS2, prior to membrane fusion which is essential to release the viral contents into the host cell cytosol. Once the virus enters the cell, it turns the cell into a factory, making millions of copies of itself which are then breathed or coughed out to infect others. Though asymptomatic/mild cases account for large number of cases, it is also postulated that the viral load is higher in pre-symptomatic cases compared to those with severe disease thereby making them most important overlooked viral shedders contributing to highly contagiousness of the infection. Therefore, early diagnosis of Covid-19 is critical for prevention and control of this pandemic and the clinical characteristics alone cannot define the diagnosis of Covid-19, especially for pre-symptomatic and asymptomatic patients.

Nuclei acid detection based approaches have become a rapid and reliable technology for detection of virus, and amongst them real time Reverse Transcriptase-Polymerase Chain Reaction (RTPCR) is considered as the 'Gold standard' for the detection SARSCoV-2. The real time RT-PCR has adequate sensitivity and high specificity in the diagnosis Covid-19 particularly the early infection. However, the important drawback with RT-PCR application is the risk of eliciting false-negative results which in the current pandemic can be perilous and a major impediment in the containment of outbreaks. It is reported that many 'suspected' cases with typical clinical characteristics of Covid-19 and diagnostic computed tomography (CT) images were not diagnosed with RT-PCR [15]. Thus, a negative result does not exclude the possibility of Covid-19 infection entirely and therefore should not be used as the only criterion in the management of Covid-19 cases. There are multitudes of factors that affect the RT-PCR test results and these can be in any of the pre-analytical, analytical and post analytical phases. Further, laboratory practices and personnel skill in technical and safety procedures also explain some of the false-negative results.

SARS-CoV2 is being acknowledged as a systemic infection and affects haematological parameters as well. The hallmark of SARSCoV2 pathogenesis is the cytokine storm. It is revealed by various studies that plasma concentrations of IL-6, IL- $1 \beta$, TNF- $\alpha$, G-CSF, IP10 are very high in Covid-19 patients and even higher in Intensive Care Unit (ICU) patients than non-ICU patients. It is propounded in previous studies that this cytokine release syndrome in Covid-19 patients is responsible for the lymphopenia which has been related to significant decrease in T-lymphocytes (CD8 + T Cells) and positively correlates with in-hospital deaths and severity of illness [17-20].

\section{Materials and Methods}

\section{Search strategy and selection criteria}

The preferred reporting items for systematic review and meta-analysis protocols methodology was used in the search strategy. A systematic search was made in the following databases: PubMed/Medline/Embase/Cinah1/web of science from database inception until 31 Oct 2020. The search strings utilized were 'Coronaviridae'(terms), 'Coronavirus infections' (MESH terms), 'Coronavirus infections (All fields). After screening the aforementioned databases, the search was supplemented by reviews of references covering our topic of interest.

\section{Population}

The geographic scope of the investigation comprises of panIndia with individuals reporting from various states to the duty station and is akin to national investigation. The study is therefore representative of the overall burden of infection i.e including both high and low incidence areas.

\section{Sampling}

All individuals serving in the organisation and their dependents, reporting to duty station and are in the age group between 23 and 58 yrs. The individuals were initially screened at the screening kiosk set up at the Point of Entry with a set of screening questionnaire and then directed to the quarantine facility where they were quarantined for a period of 21 days adhering to strict quarantine protocol as per the WHO enunciated Quarantine protocol. Symptomatic individuals were referred to the Flu clinic where the patients were further evaluated for any complaints of fever, headache, body ache, malaise, cough and other features of Covid-19. Baseline investigations were carried out including Complete Blood Count, Peripheral blood smear, Renal function tests, Liver function tests and Urine routine \& microscopy maintaining universal precautions. Individuals who are Suspect Covid-19 were admitted in the Suspect ward of the isolation facility of the hospital which was well segregated from the Covid-19 isolation facility. All individuals who were suspect Covid-19 underwent sampling with Nasopharyngeal and Oropharyngeal swabs for RT-PCR testing in a designated Sample Collection Centre of the hospital. The swabs were then inoculated into a viral transport media and transported under cold chain to ICMR approved VRDL (Viral Research and Diagnostic Laboratory) at a nearby Government hospital. 
Study on the Effects of Sars-Cov-2 Infection on the Hematological and Biochemical Parameters and Clinicopathological Correlation in the Evolution of Covid-19

Individuals were also subjected to the RT-PCR testing for Covid-19 when they were found to be high-risk contacts during contact tracing of laboratory confirmed Covid-19 cases. In these cases, all such individuals were sampled for testing between day 7 and day 10 of coming in contact with a laboratory confirmed Covid-19 case or on developing symptoms of fever, nausea, vomiting, rhinorrhoea, cough and other respiratory symptoms, whichever was earlier.

The hospital had the advantage of investigating the patients at the very outset, in the pre-symptomatic stage of the disease, where the patients presented with minimal or no symptoms and signs of the disease. This early study of the patients with baseline investigations was very informative and helpful in detecting asymptomatic viral shedders who would otherwise have had managed to spread the disease in the environment defeating the very purpose of quarantine and also helping in the study of the evolution of Covid-19 and its impact on the hematopoietic system and hemostasis.

\section{Inclusion criteria}

All RT-PCR positive patients admitted in the Isolation facility of the peripheral mid-zonal military hospital. These individuals initially reported to the respiratory clinic or were quarantined in a quarantine facility. The patient categories were as under:

- All symptomatic individuals quarantined in the quarantine facility, who later turned positive for Covid-19 on RT-PCR testing.
- All high-risk contacts of lab confirmed cases sampled between day 7 and day 14 of coming in contact with Covid-19 positive case.

- All symptomatic Health Care Workers (HCW) working in the frontline Covid duties who turned Covid-19 positive by RTPCR testing.

- All pregnant women approaching labour or within 5 days of expected date of delivery, who turned positive by RT-PCR testing.

- All individuals who were declared Covid-19 positive on being sampled on arrival at the airport.

\section{Exclusion criteria}

All Suspect Covid-19 individuals who turned negative with atleast two RT-PCR testings.

\section{Methodology}

Sample size

A total of 250 patients were admitted between 20 Jun and 18 Oct 2020 in a peripheral mid-zonal Military Hospital and were tested Covid-19 positive by RT-PCR, which is considered the gold standard for the diagnosis of Covid-19. The list of patients with the symptomatology is as per the table 1 . The samples collected were both Nasopharyngeal and Oropharyngeal swabs in the designated Sample Collection Centre of the hospital. The technique of collection and despatch employed was as under:

\begin{tabular}{|c|c|c|c|c|c|c|}
\hline Ser No & $\begin{array}{c}\text { Covid-19 positive } \\
\text { patient }\end{array}$ & $\begin{array}{c}\text { Date of Sample } \\
\text { Collection }\end{array}$ & Symptoms & $\begin{array}{c}\text { History of } \\
\text { travel by Air }\end{array}$ & $\begin{array}{c}\text { History of } \\
\text { travel by Train }\end{array}$ & $\begin{array}{c}\text { History of travel } \\
\text { by Road }\end{array}$ \\
\hline 1 & $36 \mathrm{yr} / \mathrm{Male}$ & 20-Jun-20 & Mild & Yes & No & No \\
\hline 2 & $22 \mathrm{yr} / \mathrm{Male}$ & 20-Jun-20 & Mild & Yes & No & No \\
\hline 3 & $36 \mathrm{yr} / \mathrm{Male}$ & 25-Jun-20 & Mild & Yes & No & No \\
\hline 4 & $25 \mathrm{yr} / \mathrm{Male}$ & 25-Jun-20 & No & No & No & No \\
\hline 5 & 27 yr /Male & 25-Jun-20 & No & No & No & No \\
\hline 6 & $33 \mathrm{yr} / \mathrm{Male}$ & 25-Jun-20 & No & No & No & No \\
\hline 7 & $29 \mathrm{yr} / \mathrm{Male}$ & 26-Jun-20 & No & Yes & No & No \\
\hline 8 & $33 \mathrm{yr} /$ Male & 29-Jun-20 & No & Yes & No & No \\
\hline 9 & $29 \mathrm{Yr} / \mathrm{Male}$ & 29-Jun-20 & No & No & No & No \\
\hline 10 & $38 \mathrm{Yr} / \mathrm{Male}$ & 29-Jun-20 & No & No & No & No \\
\hline 11 & $29 \mathrm{yr} / \mathrm{Male}$ & 29-Jun-20 & No & No & No & No \\
\hline
\end{tabular}


Study on the Effects of Sars-Cov-2 Infection on the Hematological and Biochemical Parameters and Clinicopathological Correlation in the Evolution of Covid-19

\begin{tabular}{|c|c|c|c|c|c|c|}
\hline 12 & 24yr/Male & 29-Jun-20 & No & No & No & No \\
\hline 13 & 27yr/Male & 29-Jun-20 & No & No & No & No \\
\hline 14 & 35yr/Male & 29-Jun-20 & No & No & No & No \\
\hline 15 & 27yr/Male & 29-Jun-20 & No & No & No & No \\
\hline 16 & 23yr/Male & 29-Jun-20 & No & Yes & No & No \\
\hline 17 & 38yr/Male & 29-Jun-20 & No & No & No & No \\
\hline 18 & 41yr/Male & 01-Jul-20 & Mild & Yes & No & No \\
\hline 19 & 28yr/Male & 30-Jun-20 & No & No & No & No \\
\hline 20 & 28yr/Male & 03-Jul-20 & No & No & No & No \\
\hline 21 & 42yr/Male & 03-Jul-20 & No & No & No & No \\
\hline 22 & 28yr/Male & 03-Jul-20 & No & No & No & No \\
\hline 23 & 26yr/Male & 03-Jul-20 & Mild & Yes & No & No \\
\hline 24 & 28yr/Male & 08-Jul-20 & Mild & Yes & No & No \\
\hline 25 & 37yr/Male & 04-Jul-20 & Mild & Yes & No & No \\
\hline 26 & 26yr/Male & 08-Jul-20 & No & No & No & No \\
\hline 27 & 28yr/Male & 08-Jul-20 & No & No & No & No \\
\hline 28 & 24yr/Male & 08-Jul-20 & No & No & No & No \\
\hline 29 & 26yr/Male & 08-Jul-20 & No & No & No & No \\
\hline 30 & 24yr/Male & 08-Jul-20 & No & No & No & No \\
\hline 31 & 34yr/Male & 22-Jun-20 & No & No & No & No \\
\hline 32 & $30 \mathrm{yr} /$ Male & 08-Jul-20 & No & No & No & No \\
\hline 33 & 49yr/Male & 06-Jul-20 & No & Yes & No & No \\
\hline 34 & 24yr/Male & 09-Jul-20 & Mild & No & No & No \\
\hline 35 & 29yr/Male & 09-Jul-20 & No & No & No & No \\
\hline 36 & 31yr/Male & 09-Jul-20 & No & No & No & No \\
\hline 37 & 23yr/Male & 15-Jul-20 & No & Yes & No & No \\
\hline 38 & 23yr/Male & 15-Jul-20 & Mild & No & No & No \\
\hline 39 & 28yr/Male & 15-Jul-20 & Moderate & Yes & No & No \\
\hline 40 & $35 \mathrm{yr} /$ Male & 20-Jul-20 & Mild & No & Yes & No \\
\hline 41 & 25yr/Male & 22-Jul-20 & Mild & No & No & Yes \\
\hline 42 & 32yr/Male & 19-Jul-20 & Mild & Yes & No & No \\
\hline 43 & 30yr/Male & 22-Jun-20 & Mild & Yes & No & No \\
\hline 44 & 22yr/Male & 22-Jul-20 & Mild & Yes & No & No \\
\hline 45 & 42yr/Male & 22-Jul-20 & Mild & Yes & No & No \\
\hline 46 & 43yr/Male & 23-Jul-20 & No & Yes & Yes & No \\
\hline 47 & 33yr/Male & 23-Jul-20 & No & Yes & No & No \\
\hline 48 & 24yr/Male & 29-Jul-20 & Mild & No & No & Yes \\
\hline
\end{tabular}


Study on the Effects of Sars-Cov-2 Infection on the Hematological and Biochemical Parameters and Clinicopathological Correlation in the Evolution of Covid-19

\begin{tabular}{|c|c|c|c|c|c|c|}
\hline 49 & 24yr/Male & 29-Jul-20 & Mild & No & No & Yes \\
\hline 50 & 44yr/Male & 29-Jul-20 & Mild & Yes & No & Yes \\
\hline 51 & 39yr/Male & 29-Jul-20 & Mild & No & No & Yes \\
\hline 52 & 24yr/Male & 29-Jul-20 & Mild & No & No & No \\
\hline 53 & 26yr/Male & 29-Jul-20 & Mild & No & No & No \\
\hline 54 & 35yr/Male & 28-Jul-20 & Mild & Yes & No & Yes \\
\hline 55 & 30yr/Male & 30-Jul-20 & Mild & No & No & Yes \\
\hline 56 & 33yr/Male & 01-Aug-20 & Moderate & No & Yes & No \\
\hline 57 & 31yr/Male & 01-Aug-20 & Mild & No & No & Yes \\
\hline 58 & 31yr/Male & 05-Aug-20 & Mild & Yes & No & No \\
\hline 59 & 26yr/Male & 05-Aug-20 & Mild & Yes & No & No \\
\hline 60 & 26yr/Male & 05-Aug-20 & Mild & No & Yes & No \\
\hline 61 & 26yr/Male & 05-Aug-20 & Mild & Yes & No & No \\
\hline 62 & 26yr/Male & 05-Aug-20 & Mild & Yes & No & No \\
\hline 63 & 30yr/Male & 05-Aug-20 & Moderate & No & No & Yes \\
\hline 64 & 30yr/Male & 05-Aug-20 & Moderate & No & No & No \\
\hline 65 & 30yr/Male & 04-Aug-20 & Mild & No & Yes & No \\
\hline 66 & 29yr/Male & 05-Aug-20 & Mild & No & No & No \\
\hline 67 & 30yr/Male & 05-Aug-20 & Mild & Yes & No & No \\
\hline 68 & 30yr/Male & 05-Aug-20 & Mild & No & No & Yes \\
\hline 69 & 30yr/Male & 05-Aug-20 & Mild & No & Yes & No \\
\hline 70 & 30yr/Male & 05-Aug-20 & Mild & No & Yes & No \\
\hline 71 & 29yr/Male & 05-Aug-20 & Mild & Yes & No & No \\
\hline 72 & 30yr/Male & 05 -Aug-20 & Mild & Yes & No & No \\
\hline 73 & 30yr/Male & 05-Aug-20 & Mild & No & No & No \\
\hline 74 & 32yr/Male & 05-Aug-20 & Mild & Yes & No & No \\
\hline 75 & 28yr/Male & 05-Aug-20 & Mild & No & Yes & No \\
\hline 76 & 35yr/Male & 05 -Aug-20 & Mild & Yes & No & No \\
\hline 77 & 36yr/Male & 03-Aug-20 & Moderate & Yes & No & Yes \\
\hline 78 & 28yr/Male & 09-Aug-20 & Mild & Yes & No & Yes \\
\hline 79 & 36yr/Male & 10-Aug-20 & Mild & Yes & No & No \\
\hline 80 & 40yr/Male & 10-Aug-20 & Moderate & Yes & No & No \\
\hline 81 & $37 \mathrm{yr} /$ Male & 10-Aug-20 & Mild & No & Yes & No \\
\hline 82 & $39 \mathrm{yr} /$ Male & 10 -Aug-20 & Moderate & No & Yes & No \\
\hline 83 & 36yr/Male & 12-Aug-20 & Mild & Yes & No & No \\
\hline 84 & $33 \mathrm{yr} / \mathrm{Male}$ & 17 -Aug-20 & Mild & No & Yes & No \\
\hline
\end{tabular}


Study on the Effects of Sars-Cov-2 Infection on the Hematological and Biochemical Parameters and Clinicopathological Correlation in the Evolution of Covid-19

\begin{tabular}{|c|c|c|c|c|c|c|}
\hline 85 & 36yr/Male & 17-Aug-20 & Moderate & No & No & No \\
\hline 86 & 34yr/Male & 17-Aug-20 & No & No & No & Yes \\
\hline 87 & 34yr/Male & 18-Aug-20 & Mild & No & No & Yes \\
\hline 88 & $30 \mathrm{yr} /$ Male & 17-Aug-20 & Mild & Yes & No & Yes \\
\hline 89 & 26yr/Male & 17-Aug-20 & Mild & No & No & Yes \\
\hline 90 & 29yr/Male & 20-Aug-20 & No & Yes & No & No \\
\hline 91 & 35yr/Male & 20-Aug-20 & Mild & Yes & No & No \\
\hline 92 & 41yr/Male & 20-Aug-20 & Moderate & Yes & No & No \\
\hline 93 & 46yr/Male & 22-Aug-20 & Mild & No & No & Yes \\
\hline 94 & $32 \mathrm{yr} / \mathrm{Male}$ & 24-Aug-20 & Mild & Yes & No & No \\
\hline 95 & 30yr/Male & 24-Aug-20 & Mild & No & Yes & No \\
\hline 96 & $28 \mathrm{yr} / \mathrm{Male}$ & 24-Aug-20 & No & No & Yes & No \\
\hline 97 & 39yr/Male & 24-Aug-20 & Mild & Yes & No & No \\
\hline 98 & $32 \mathrm{yr} / \mathrm{Male}$ & 24-Aug-20 & Mild & No & Yes & Yes \\
\hline 99 & $31 \mathrm{yr} / \mathrm{Male}$ & 24-Aug-20 & Mild & No & Yes & Yes \\
\hline 100 & $33 \mathrm{yr} / \mathrm{Male}$ & 24-Aug-20 & Mild & Yes & No & No \\
\hline 101 & $45 \mathrm{yr} / \mathrm{Male}$ & 24-Aug-20 & Mild & Yes & No & No \\
\hline 102 & $41 \mathrm{yr} / \mathrm{Male}$ & 25-Aug-20 & Mild & No & Yes & Yes \\
\hline 103 & $32 \mathrm{yr} /$ Male & 23-Aug-20 & No & No & No & No \\
\hline 104 & $46 \mathrm{yr} / \mathrm{Male}$ & 26-Aug-20 & Moderate & Yes & Yes & No \\
\hline 105 & $40 \mathrm{yr} / \mathrm{Male}$ & 26-Aug-20 & Mild & No & No & No \\
\hline 106 & $45 \mathrm{yr} / \mathrm{Male}$ & 26-Aug-20 & Moderate & Yes & No & yes \\
\hline 107 & $40 \mathrm{yr} / \mathrm{Male}$ & 26-Aug-20 & Mild & Yes & No & No \\
\hline 108 & $35 \mathrm{yr} /$ Male & 26-Aug-20 & Mild & No & Yes & No \\
\hline 109 & 37yr/Male & 25-Aug-20 & Mild & Yes & No & No \\
\hline 110 & $43 \mathrm{yr} /$ Male & 27-Aug-20 & Mild & Yes & No & No \\
\hline 111 & $39 \mathrm{yr} / \mathrm{Male}$ & 27-Aug-20 & Mild & No & No & No \\
\hline 112 & 43yr/Male & 27-Aug-20 & Mild & No & Yes & No \\
\hline 113 & 38yr/Male & 29-Aug-20 & Moderate & Yes & No & No \\
\hline 114 & $36 \mathrm{yr} / \mathrm{Male}$ & 29-Aug-20 & Mild & Yes & No & No \\
\hline 115 & $28 \mathrm{yr} /$ Female & 29-Aug-20 & Moderate & No & No & No \\
\hline 116 & 38yr/Male & 29-Aug-20 & Mild & No & Yes & No \\
\hline 117 & $35 \mathrm{yr} /$ Male & 29-Aug-20 & Mild & Yes & Yes & No \\
\hline 118 & $28 \mathrm{yr} / \mathrm{Male}$ & 29-Aug-20 & Mild & Yes & No & Yes \\
\hline 119 & $32 \mathrm{yr} / \mathrm{Male}$ & 29-Aug-20 & Mild & No & No & No \\
\hline 120 & 38yr/Male & 31-Aug-20 & Mild & Yes & No & No \\
\hline 121 & 55yr/Male & 28-Aug-20 & Mild & Yes & No & Yes \\
\hline 122 & 25yr/Male & 01-Sep-20 & No & Yes & No & Yes \\
\hline 123 & 20yr/Male & 31-Aug-20 & Mild & No & No & Yes \\
\hline 124 & 55yr/Male & 31-Aug-20 & Mild & No & No & No \\
\hline 125 & 28yr/Male & 31-Aug-20 & Mild & Yes & No & No \\
\hline 126 & 25 yrs/Male & 01-Sep-20 & Mild & Yes & Yes & No \\
\hline
\end{tabular}


Study on the Effects of Sars-Cov-2 Infection on the Hematological and Biochemical Parameters and Clinicopathological Correlation in the Evolution of Covid-19

\begin{tabular}{|c|c|c|c|c|c|c|}
\hline 127 & 29yr/Male & 01-Sep-20 & Mild & No & Yes & No \\
\hline 128 & 31 yrs/Male & 01-Sep-20 & Mild & Yes & No & No \\
\hline 129 & 30 yrs/Male & 02-Sep-20 & Mild & No & No & No \\
\hline 130 & 38yr/Male & 02-Sep-20 & No & Yes & No & Yes \\
\hline 131 & 46yr/Male & 03-Sep-20 & No & No & Yes & No \\
\hline 132 & 25yr/Male & 03-Sep-20 & Mild & Yes & No & No \\
\hline 133 & 26yr/Male & 03-Sep-20 & Mild & No & Yes & Yes \\
\hline 134 & 47yr/Male & 03-Sep-20 & Mild & No & Yes & Yes \\
\hline 135 & $25 \mathrm{yr} / \mathrm{Male}$ & 03-Sep-20 & Mild & No & No & Yes \\
\hline 136 & $32 \mathrm{yr} /$ Male & 03-Sep-20 & Mild & Yes & No & Yes \\
\hline 137 & 33 yr/Male & 03-Sep-20 & Mild & Yes & No & No \\
\hline 138 & $27 \mathrm{yr} / \mathrm{Male}$ & 03-Sep-20 & Mild & Yes & No & No \\
\hline 139 & 29yr/Male & 03-Sep-20 & Mild & No & Yes & No \\
\hline 140 & $25 \mathrm{yr} / \mathrm{Male}$ & 03-Sep-20 & Mild & No & No & No \\
\hline 141 & $31 \mathrm{yr} /$ Male & 03-Sep-20 & Mild & Yes & No & No \\
\hline 142 & $26 \mathrm{yr} / \mathrm{Male}$ & 03-Sep-20 & Mild & No & No & No \\
\hline 143 & 26yr/Male & 03-Sep-20 & Mild & Yes & No & No \\
\hline 144 & 25yr/Male & 05-Sep-20 & Mild & Yes & Yes & No \\
\hline 145 & 41yr/Male & 06-Sep-20 & No & Yes & No & No \\
\hline 146 & $43 \mathrm{yr} / \mathrm{Male}$ & 07-Sep-20 & Mild & No & Yes & No \\
\hline 146 & 41yr/Male & 07-Sep-20 & Mild & Yes & No & No \\
\hline 147 & $29 \mathrm{yr} /$ Male & 07-Sep-20 & Mild & Yes & No & Yes \\
\hline 148 & 32 yr/Male & 07-Sep-20 & Mild & No & Yes & No \\
\hline 149 & 33 yr/Male & 07-Sep-20 & Mild & Yes & No & No \\
\hline 150 & 36 yr/Male & 07-Sep-20 & Mild & No & No & No \\
\hline 151 & $27 \mathrm{yr} / \mathrm{Male}$ & 08-Sep-20 & Mild & Yes & No & No \\
\hline 152 & 33yr/Male & 08-Sep-20 & Mild & No & No & Yes \\
\hline 153 & 36yr/Male & 08-Sep-20 & Mild & No & No & Yes \\
\hline 154 & $29 \mathrm{yr} /$ Female & 08-Sep-20 & Mild & No & No & No \\
\hline 155 & $42 \mathrm{yr} / \mathrm{Male}$ & 08-Sep-20 & Mild & No & No & No \\
\hline 156 & $28 \mathrm{yr} / \mathrm{Male}$ & 08-Sep-20 & Mild & Yes & No & No \\
\hline 157 & $31 \mathrm{yr} /$ Male & 08-Sep-20 & Mild & Yes & Yes & No \\
\hline 158 & $37 \mathrm{yr} /$ Male & 07 Sep 20 & Mild & Yes & No & No \\
\hline 159 & 34 yr/Male & 10-Sep-20 & Mild & Yes & No & Yes \\
\hline 160 & 33 yr/Female & 07-Sep-20 & Mild & No & No & No \\
\hline 161 & $28 \mathrm{yr} /$ Female & 10-Sep-20 & Mild & No & No & No \\
\hline 162 & $39 \mathrm{yr} /$ Male & 11-Sep-20 & Mild & No & Yes & Yes \\
\hline 163 & $40 \mathrm{yr} / \mathrm{Male}$ & 12-Sep-20 & Mild & No & No & Yes \\
\hline 164 & 43yr/Male & 13-Sep-20 & Mild & Yes & No & No \\
\hline 165 & 57yr/Male & 14-Sep-20 & Mild & Yes & No & No \\
\hline 166 & 31yr/Male & 14-Sep-20 & No & Yes & No & No \\
\hline 167 & 33yr/Male & 14-Sep-20 & Mild & Yes & Yes & No \\
\hline
\end{tabular}


Study on the Effects of Sars-Cov-2 Infection on the Hematological and Biochemical Parameters and Clinicopathological Correlation in the Evolution of Covid-19

\begin{tabular}{|c|c|c|c|c|c|c|}
\hline 168 & 42 yr/Male & 14-Sep-20 & Mild & Yes & No & No \\
\hline 169 & $45 \mathrm{yr} /$ Male & 14-Sep-20 & Mild & Yes & No & No \\
\hline 170 & 39 yr/Male & 14-Sep-20 & Mild & Yes & No & No \\
\hline 171 & $35 \mathrm{yr} /$ Female & 16-Sep-20 & Moderate & No & No & No \\
\hline 172 & 39 yr/Male & 16-Sep-20 & Mild & No & No & Yes \\
\hline 173 & 41yr/Male & 16-Sep-20 & Mild & Yes & No & No \\
\hline 174 & 30yr/Male & 17-Sep-20 & Mild & Yes & No & Yes \\
\hline 175 & 33yr/Male & 17-Sep-20 & No & Yes & No & No \\
\hline 176 & 32yr/Male & 17-Sep-20 & Mild & No & Yes & Yes \\
\hline 177 & 45 yr/Male & 22-Sep-20 & Mild & No & No & No \\
\hline 178 & 30Yr/Male & 22-Sep-20 & Mild & No & No & No \\
\hline 179 & 35yr/Male & 21-Sep-20 & Mild & Yes & No & Yes \\
\hline 180 & 28yr/Male & 25-Sep-20 & Mild & Yes & Yes & No \\
\hline 181 & 46yr/Male & 25-Sep-20 & No & Yes & No & No \\
\hline 182 & 39 yr /Male & 25-Sep-20 & Mild & Yes & No & No \\
\hline 183 & 28yr/Male & 26-Sep-20 & No & Yes & No & No \\
\hline 184 & 32 yr/Male & 26-Sep-20 & Mild & No & No & No \\
\hline 185 & 30yr/Male & 27-Sep-20 & No & Yes & No & No \\
\hline 186 & 30yr/Male & 28-Sep-20 & Mild & No & No & No \\
\hline 187 & $29 \mathrm{yr} / \mathrm{Male}$ & 29-Sep-20 & Mild & Yes & No & No \\
\hline 188 & 31yr/Male & 29-Sep-20 & Mild & No & Yes & No \\
\hline 189 & $40 \mathrm{yr} / \mathrm{Male}$ & 30-Sep-20 & Mild & Yes & No & No \\
\hline 190 & 37 yr/Male & 30-Sep-20 & Mild & Yes & Yes & No \\
\hline 191 & 35 yr/Male & 30-Sep-20 & Mild & Yes & No & No \\
\hline 192 & 36 yr/Male & 30-Sep-20 & Mild & Yes & No & No \\
\hline 193 & 48yr/Male & 30-Sep-20 & Moderate & Yes & No & No \\
\hline 194 & 33 yr/Male & $01-0 c t-20$ & Mild & No & Yes & No \\
\hline 195 & $31 \mathrm{yr} /$ Male & $01-$ Oct-20 & Mild & No & Yes & No \\
\hline 196 & $29 \mathrm{yr} /$ Male & 01-Oct-20 & Mild & Yes & Yes & No \\
\hline 197 & 32yr/Male & 04-Oct-20 & No & Yes & No & No \\
\hline 198 & 40yr/Male & $05-0 c t-20$ & Mild & No & No & Yes \\
\hline 199 & 39yr/Male & 05 -Oct- 20 & Mild & No & No & Yes \\
\hline 200 & $31 \mathrm{yr} /$ Male & $05-$-Oct- 20 & Mild & No & No & Yes \\
\hline 201 & 38yr/Male & $05-0 c t-20$ & Mild & No & No & Yes \\
\hline 202 & 40yr/Male & $07-$-Oct- 20 & Mild & No & No & No \\
\hline 203 & 40yr/Male & $07-0 c t-20$ & Mild & Yes & No & No \\
\hline 204 & 22yr/Male & $07-0 c t-20$ & No & No & No & Yes \\
\hline 205 & 37yr/Male & $08-0 c t-20$ & Moderate & Yes & No & No \\
\hline 206 & 32 yr/Male & $10-0 c t-20$ & Mild & Yes & No & No \\
\hline 207 & 35 yr/Male & $10-$ Oct- 20 & Mild & Yes & No & No \\
\hline 208 & 39 yr/Male & $10-0 c t-20$ & Mild & Yes & Yes & No \\
\hline 209 & 30 yr/Male & $10-0 c t-20$ & Mild & Yes & No & No \\
\hline 210 & 33 yr/Male & $10-$ Oct- 20 & Mild & Yes & No & Yes \\
\hline
\end{tabular}


Study on the Effects of Sars-Cov-2 Infection on the Hematological and Biochemical Parameters and Clinicopathological Correlation in the Evolution of Covid-19

\begin{tabular}{|c|c|c|c|c|c|c|}
\hline 211 & $35 \mathrm{yr} /$ Male & $10-0 c t-20$ & Mild & Yes & Yes & No \\
\hline 212 & $32 \mathrm{yr} / \mathrm{Male}$ & $10-0 c t-20$ & Mild & No & Yes & No \\
\hline 213 & 40yr/Male & $10-0 c t-20$ & Mild & Yes & No & No \\
\hline 214 & 24yr/Male & $10-0 c t-20$ & Mild & No & Yes & No \\
\hline 215 & 25yr/Male & $10-0 c t-20$ & Mild & Yes & No & Yes \\
\hline 216 & $29 \mathrm{yr} /$ Male & $10-0 c t-20$ & Mild & Yes & No & Yes \\
\hline 217 & $31 \mathrm{yr} / \mathrm{Male}$ & $10-0 c t-20$ & Mild & Yes & No & Yes \\
\hline 218 & $30 \mathrm{yr} / \mathrm{Male}$ & $10-0 c t-20$ & Mild & Yes & No & Yes \\
\hline 219 & $32 \mathrm{yr} / \mathrm{Male}$ & $10-0 c t-20$ & Mild & Yes & No & Yes \\
\hline 220 & $27 \mathrm{yr} / \mathrm{Male}$ & $10-0 c t-20$ & Mild & Yes & No & Yes \\
\hline 221 & 33yr/Male & $10-0 c t-20$ & Mild & No & Yes & No \\
\hline 222 & 25yr/Male & $11-0 c t-20$ & No & Yes & No & No \\
\hline 228 & $32 \mathrm{yr} /$ Male & $10-0 c t-20$ & Mild & Yes & No & No \\
\hline 229 & $30 \mathrm{yr} /$ Male & $10-0 c t-20$ & Mild & No & Yes & No \\
\hline 230 & $29 \mathrm{yr} /$ Male & $10-0 c t-20$ & Mild & Yes & No & No \\
\hline 231 & $27 \mathrm{yr} / \mathrm{Male}$ & $10-0 c t-20$ & Mild & Yes & No & No \\
\hline 232 & $28 \mathrm{yr} / \mathrm{Male}$ & $10-0 c t-20$ & Mild & Yes & No & No \\
\hline 233 & $31 \mathrm{yr} /$ Male & $10-0 c t-20$ & Mild & Yes & No & No \\
\hline 234 & $32 \mathrm{yr} /$ Male & $12-0 c t-20$ & Mild & No & Yes & No \\
\hline 235 & 27yr /Male & $13-0 c t-20$ & Mild & No & No & Yes \\
\hline 236 & 41yr/Male & $13-0 c t-20$ & Mild & Yes & No & No \\
\hline 237 & 24yr/Male & $14-0 c t-20$ & Mild & Yes & No & No \\
\hline 238 & 23yr/Male & $14-0 c t-20$ & Mild & Yes & No & Yes \\
\hline 239 & 21yr/Male & $14-0 c t-20$ & Mild & Yes & No & Yes \\
\hline 240 & 24yr/Male & $14-0 c t-20$ & Mild & Yes & Yes & No \\
\hline 241 & 25yr/Male & $15-0 c t-20$ & Mild & Yes & No & No \\
\hline 242 & 26yr/Male & $16-0 c t-20$ & Mild & No & No & No \\
\hline 243 & 43yr/Male & $16-0 c t-20$ & Mild & Yes & No & No \\
\hline 244 & 27yr/Male & $16-0 c t-20$ & Mild & No & No & Yes \\
\hline 245 & $32 \mathrm{yr} /$ Male & $16-0 c t-20$ & Mild & No & Yes & No \\
\hline 246 & $41 \mathrm{yr} /$ Male & $16-0 c t-20$ & Mild & Yes & No & No \\
\hline 247 & 44yr/Male & $16-0 c t-20$ & Mild & No & No & Yes \\
\hline 248 & 30yr/Male & $17-0 c t-20$ & Moderate & Yes & No & No \\
\hline 249 & 28yr/Male & $17-0 c t-20$ & Mild & Yes & No & No \\
\hline 250 & 42yr/Male & $17-0 c t-20$ & Mild & Yes & No & No \\
\hline
\end{tabular}

Table 1: The list of all Covid-19 positive patients admitted in the hospital between Jun 20 and Oct 20.

Collection of Nasopharyngeal swab

With the patient's head tilted back to $70^{\circ}$, a nasopharyngeal swab is inserted into the nostril to reach the depth till a resistance is felt when the swab is left in situ for a few seconds to absorb secretions and by gently rotating, the swab is removed. The tip of the swab is then placed into the VTM and the rest of the applicator stick is cut. The cap of the lid is then tightly screwed and sealed with the Paraffin paper. The VTM vial is then labelled with the details of the patient and the SRF (Special requisition form) identity generated online with the RT-PCR application. 


\section{Collection of oropharyngeal swab}

With the tongue of the patient held away by a tongue depressor, the posterior oropharyngeal wall and the tonsillar pillars are swabbed by a sweeping motion. Without touching the soft palate and the tongue, the swab is gently retrieved and the tip of the swab is then placed in the VTM and the rest of the applicator stick is cut. The cap of the lid is then tightly screwed and sealed with the Paraffin paper. The VTM vial is then labelled with the details of the patient and the SRF (Special requisition form) identity generated online with the RT-PCR application.

\section{Packaging of the containers}

The VTM vials are covered using adsorbent material and the vials are packaged by Triple packing, comprising of plastic containers and zip-lock pouch. Completing the Referral form the containers were dispatched to the ICMR approved Viral Research and Diagnostic Laboratory maintaining adequate cold chain in the form of ice box with the containers surrounded by hard frozen gel packs.

\section{Specimens collected}

Whole blood samples were collected in EDTA, sodium fluoride and sterile vacutainers while urine samples were collected in sterile, single use, disposable containers as per the laboratory and biosafety guidelines found in the WHO Laboratory Biosafety Manual, $3^{\text {rd }}$ edition. Laboratory procedures involving sample manipulation were carried out in a biosafety cabinet.

\section{Specimen collection}

All blood samples were collected from the patients admitted in Isolation facility. All those involved in specimen collection and transportation to the laboratory were trained in safe specimen handling practices and spill decontamination procedures and Infection Prevention and Control measures.

\section{Definition of various terms}

Duty station

Refers to the Military Station where Military garrivalison and units are established along with the Military Hospital.

\section{Quarantine}

Quarantine of persons is limitation of activities of or the separation of such well persons who are not ill but who may have been exposed to an infectious agent or disease, with the objective of monitoring their symptoms and ensuring the early detection of cases. It applies to individuals coming from a disease affected area to an area where the disease has not occurred. A designated area, referred to Quarantine (Q) facility, was earmarked wherein all individuals with history of travel from Covid hotspot or contact with suspected/confirmed Covid-19 case in the last 14 days were lodged. All such individuals were quarantined for a total duration of 21 days in small cohorts of 05 persons only within whom any interaction was allowed.

\section{Isolation}

Isolation refers to separation, for the period of communicability, of infected persons from others in such places and under such conditions, as to prevent or limit the direct or indirect transmission of the infectious agent from those infected to those who are susceptible or who may spread the agent to others. It applies to individuals having symptoms/signs/of the disease under question and requires medical care in a health care setting. A designated facility was created within the hospital premises wherein all laboratory confirmed Covid-19 cases were admitted and treated. All Covid-19 positive patients were treated in the facility till they tested negative either by RT-PCR or by Rapid Antigen Test. The testing was carrivalied out after 10 days of the initial sample that yielded a positive result or after 03 days of clinical recovery, whichever is later.

\section{Suspect case}

Any patient with acute respiratory illness/fever with atleast one symptom/sign of respiratory disease eg: cough, shortness of breath AND with no other etiology that fully explains the clinical presentation AND a history of travel to or residence in a country/ area/territory reporting local transmission of Covid-19 disease during the 14 days prior to the onset of symptoms.

\section{OR}

A patient with acute respiratory illness AND having been in contact with Confirmed Covid-19 case in the last 14 days prior to the onset of symptoms.

OR

A patient with severe acute respiratory infection (fever and atleast one sign/symptom of respiratory disease eg: cough, shortness of breath) AND requiring hospitalization AND with no other etiology that fully explains the clinical presentation.

\section{Confirmed case}

A person with laboratory confirmation of Covid-19 infection irrespective of clinical signs and symptoms. 
Study on the Effects of Sars-Cov-2 Infection on the Hematological and Biochemical Parameters and Clinicopathological Correlation in the Evolution of Covid-19

Contact

A contact is a person who has experienced any one of the following exposures during the 2 days before and the 14 days after the onset of symptoms of a probable or confirmed case:

- Face to face contact with a probable or confirmed case within 1 meter and for atleast 15 minutes.

- Direct physical contact with a probable or confirmed Covid-19 case

- Direct care of a patient with probable or confirmed Covid-19 disease without using recommended Personal Protective Equipment (PPE).

- Other situations as indicated by local risk assessments.

\section{High-risk contacts}

Refers to any person who has had any of the following:

- Touched body fluids of the patient (respiratory tract secretions, blood, vomit, saliva, urine, faeces).

- Had direct physical contact with the body of the patient including physical examination without PPE

- Touched or cleaned the linen, clothes or dishes of the patient

- Lives in the same household as the patient

- Been in close proximity (within 1 meter) of the confirmed case without precautions

- Been a passenger in close proximity (within 1 meter) for more than 6 hours, in a conveyance with a symptomatic person who later tested positive for Covid-19.

Low risk contacts

Refers to any person who has:

- Shared the same space (same class for school/worked in the same room/office) and not having high-risk exposure to confirmed case of Covid-19.
- Travelled in same environment (bus/train/flight/any mode of transit) but not having a high-risk exposure.

\section{Laboratory biosafety}

The laboratory procedures included haematological assessment by semi-automated hematanalyser and Peripheral Blood smear examination, biochemistry panel by semi-automated analyser and urine examination by semi-automated analyser and urine microscopic examination. All examinations were performed based on risk assessment and only by personnel with demonstrated capability, in strict observance of all relevant protocols at all times. All specimens intended for hematology and biochemistry analyses were handled as per standard guidelines without additional measures as per WHO Laboratory Biosafety Manual, $3^{\text {rd }}$ edition.

When handling and processing specimens, including blood for serological testing and urine for microscopy, laboratory practices and procedures that are basic to Good Microbiological Practice and Procedure (GMPP) were followed. The Point of Care (POC) assays were carrivalied out on a bench without employing a biosafety cabinet but ensuring universal precautions and in a well-ventilated area free of clutter. Area and surface disinfection were carrivalied out using disinfectants with proven activity against enveloped viruses, including Sodium hypochlorite (bleach: for example, 1000 parts per million (ppm) $(0.1 \%)$ for general surface disinfection and 10,000 ppm (1\%) for disinfection of sample spills: 70\% ethanol: $0.5 \%$ Hydrogen peroxide. Particular attention was paid to not only to the selection of the disinfectant but also the contact time, dilution, shelf-life and expiry date after the working solution was prepared.

\section{Haematological and biochemistry parameters}

The haematological and biochemical profiles of patients admitted in the Isolation ward are as depicted in the tables 2 and 3 daywise. Asymptomatic and those with mild to moderate disease were assessed following both Universal and Covid precautions.

\begin{tabular}{|c|c|c|c|c|c|c|c|c|}
\hline SI NO & $\begin{array}{c}\text { Date of } \\
\text { Investigation }\end{array}$ & Haemoglobin & $\begin{array}{c}\text { Total } \\
\text { Leukocyte } \\
\text { count }\end{array}$ & $\begin{array}{c}\text { Polymorphs } \\
\text { (\%) }\end{array}$ & $\begin{array}{c}\text { Lymphocyte } \\
\text { (\%) }\end{array}$ & $\begin{array}{c}\text { Monocyte } \\
\text { (\%) }\end{array}$ & $\begin{array}{c}\text { Eosinophils } \\
(\%)\end{array}$ & $\begin{array}{l}\text { Platelet count } \\
\text { (per cmm) }\end{array}$ \\
\hline \multirow{3}{*}{1} & 06 Jun20 & 14.2 & 4000 & 55 & 38 & 2 & 5 & 160000 \\
\hline & 23-Jun-20 & 13.5 & 4000 & 52 & 40 & 3 & 5 & 150000 \\
\hline & 28-Jun & 14.9 & 4800 & 55 & 37 & 3 & 5 & 229000 \\
\hline \multirow{3}{*}{2} & 21-Jun & 14.8 & 4800 & 45 & 45 & 3 & 7 & 216000 \\
\hline & 23 Jun20 & 15.5 & 5500 & 50 & 42 & 3 & 5 & 221000 \\
\hline & 28 Jun20 & 15.4 & 7200 & 38 & 58 & 2 & 2 & 247000 \\
\hline
\end{tabular}


Study on the Effects of Sars-Cov-2 Infection on the Hematological and Biochemical Parameters and Clinicopathological Correlation in the Evolution of Covid-19

\begin{tabular}{|c|c|c|c|c|c|c|c|c|}
\hline \multirow{2}{*}{3} & 26 Jun 20 & 17.3 & 7200 & 42 & 48 & 3 & 7 & 185000 \\
\hline & 28 Jun 20 & 17.5 & 8300 & 50 & 38 & 5 & 7 & 194000 \\
\hline 4 & 27 Jun20 & 17.6 & 4500 & 53 & 36 & 4 & 7 & 180000 \\
\hline 5 & 28 Jun20 & 16.4 & 6700 & 50 & 41 & 4 & 5 & 150000 \\
\hline 6 & 28 Jun20 & 16.1 & 5200 & 50 & 38 & 5 & 7 & 187000 \\
\hline 7 & 28 Jun20 & 16.3 & 6100 & 50 & 40 & 3 & 7 & 295000 \\
\hline 8 & 29 Jun20 & 13.3 & 9900 & 60 & 35 & 2 & 3 & 150000 \\
\hline 9 & 29 Jun20 & 13.5 & 4100 & 76 & 13 & 5 & 6 & 160000 \\
\hline 10 & 30 Jun20 & 17.2 & 7100 & 60 & 34 & 4 & 2 & 195000 \\
\hline 11 & 1 Jul 20 & 15.8 & 7400 & 69 & 27 & 2 & 2 & 222000 \\
\hline 12 & 1 Jul 20 & 16.1 & 2900 & 28 & 65 & 5 & 2 & 150000 \\
\hline 13 & $1 \mathrm{Jul} 20$ & 15 & 5100 & 40 & 54 & 2 & 4 & 177000 \\
\hline 14 & $1 \mathrm{Jul} 20$ & 15.6 & 5800 & 45 & 45 & 4 & 6 & 253000 \\
\hline 15 & $1 \mathrm{Jul} 20$ & 14.5 & 6400 & 40 & 50 & 2 & 8 & 210000 \\
\hline 16 & $1 \mathrm{Jul} 20$ & 14.9 & 5100 & 61 & 30 & 3 & 6 & 244000 \\
\hline \multirow{3}{*}{17} & 1 Jul 20 & 16.3 & 4800 & 40 & 50 & 3 & 7 & 150000 \\
\hline & 3 Jul 20 & 16.1 & 4700 & 42 & 55 & 2 & 1 & 150000 \\
\hline & 6 Jul 20 & 16.1 & 4200 & 40 & 50 & 3 & 7 & 175000 \\
\hline 18 & 1 Jul 20 & 15.2 & 8600 & 42 & 50 & 3 & 5 & 391000 \\
\hline 19 & $1 \mathrm{Jul} 20$ & 16.8 & 5200 & 50 & 40 & 3 & 7 & 258000 \\
\hline \multirow{5}{*}{20} & $1 \mathrm{Jul} 20$ & 18.9 & 6800 & 50 & 30 & 4 & 16 & 237000 \\
\hline & 2 Jul 20 & 18 & 6200 & 56 & 32 & 4 & 8 & 206000 \\
\hline & 4 Jul 20 & 18.4 & 5900 & 48 & 45 & 4 & 3 & 223000 \\
\hline & $5 \mathrm{Jul} 20$ & 17.6 & 5100 & 50 & 45 & 3 & 2 & 221000 \\
\hline & 6 Jul 20 & 18.1 & 4400 & 50 & 40 & 2 & 8 & 220000 \\
\hline & 9 Jul 20 & 18.2 & 6100 & 52 & 40 & 3 & 5 & 275000 \\
\hline 21 & 3 Jul 20 & 14.5 & 9200 & 78 & 20 & 1 & 1 & 190000 \\
\hline \multirow{3}{*}{22} & 4 Jul 20 & 20 & 8000 & 50 & 44 & 4 & 2 & 225000 \\
\hline & 5 Jul 20 & 15.1 & 8000 & 54 & 42 & 2 & 2 & 268000 \\
\hline & 8 Jul 20 & 14.9 & 6100 & 57 & 32 & 5 & 6 & 210000 \\
\hline 23 & 5 Jul 20 & 15.3 & 7300 & 61 & 32 & 3 & 4 & 167000 \\
\hline 24 & 5 Jul 20 & 16 & 6900 & 64 & 30 & 3 & 3 & 197000 \\
\hline 25 & 7 Jul 20 & 15.6 & 9700 & 45 & 44 & 5 & 6 & 158000 \\
\hline \multirow{9}{*}{26} & 7 Jul 20 & 15.9 & 5800 & 60 & 36 & 3 & 1 & 150000 \\
\hline & 14-Jul & 14.6 & 3000 & 47 & 48 & 3 & 2 & 150000 \\
\hline & 15 Jul 20 & 14.6 & 2300 & 58 & 36 & 4 & 2 & 150000 \\
\hline & $15 \mathrm{Jul} 20$ & 14.5 & 3000 & 70 & 27 & 1 & 2 & 162000 \\
\hline & 17-Jul & 13.9 & 3600 & 63 & 30 & 3 & 4 & 160000 \\
\hline & 18-Jul & 14.3 & 3200 & 48 & 45 & 5 & 2 & 164000 \\
\hline & 19-Jul & 14.5 & 3800 & 50 & 45 & 3 & 2 & 169000 \\
\hline & 20-Jul & 14.3 & 3500 & 38 & 58 & 3 & 1 & 214000 \\
\hline & 21-Jul & 14.8 & 3500 & 35 & 58 & 4 & 3 & 268000 \\
\hline
\end{tabular}


Study on the Effects of Sars-Cov-2 Infection on the Hematological and Biochemical Parameters and Clinicopathological Correlation in the Evolution of Covid-19

\begin{tabular}{|c|c|c|c|c|c|c|c|c|}
\hline 27 & 7 Jul 20 & 15.8 & 4800 & 40 & 52 & 4 & 4 & 152000 \\
\hline 28 & 7 Jul 20 & 15.6 & 9400 & 45 & 50 & 3 & 2 & 160000 \\
\hline 29 & 7 Jul 20 & 16.7 & 5900 & 60 & 34 & 3 & 3 & 159000 \\
\hline 30 & 8 Jul 20 & 15.6 & 6400 & 50 & 42 & 5 & 3 & 177000 \\
\hline 31 & 9 Jul 20 & 13.8 & 12300 & 78 & 16 & 2 & 4 & 214000 \\
\hline & 12 Jul 20 & 14.9 & 7100 & 55 & 38 & 3 & 4 & 165000 \\
\hline & 13 Jul 20 & 14.2 & 7800 & 67 & 26 & 3 & 4 & 175000 \\
\hline 32 & 14-Jul-20 & 14.8 & 9400 & 65 & 29 & 2 & 4 & 151000 \\
\hline 30 & $15 \mathrm{Jul} 20$ & 14.8 & 6800 & 65 & 27 & 3 & 5 & 186000 \\
\hline & 20-Jul & 14.3 & 5800 & 45 & 49 & 4 & 2 & 254000 \\
\hline & 21-Jul & 14.6 & 8400 & 48 & 45 & 3 & 4 & 347000 \\
\hline 33 & 14-Jul & 16.9 & 8100 & 50 & 40 & 4 & 6 & 176000 \\
\hline \multirow{2}{*}{34} & 14 Jul 20 & 15 & 5400 & 60 & 35 & 3 & 2 & 302000 \\
\hline & 08-Aug & 15.2 & 5400 & 25 & 69 & 3 & 3 & 150000 \\
\hline \multirow{2}{*}{35} & 14 Jul 20 & 15.7 & 7300 & 36 & 49 & 3 & 12 & 201000 \\
\hline & 18-Jul & 15.8 & 9100 & 32 & 54 & 2 & 12 & 279000 \\
\hline \multirow{3}{*}{36} & 14 Jul 20 & 14 & 3200 & 67 & 30 & 2 & 1 & 150000 \\
\hline & $15 \mathrm{Jul} 20$ & 14.3 & 3800 & 60 & 36 & 3 & 1 & 150000 \\
\hline & 20-Jul & 14.2 & 3600 & 50 & 46 & 3 & 1 & 153000 \\
\hline \multirow{2}{*}{37} & 14 Jul 20 & 16.1 & 7300 & 53 & 38 & 4 & 5 & 182000 \\
\hline & 18-Jul & 15.9 & 9100 & 52 & 34 & 4 & 10 & 187000 \\
\hline 38 & 18-Jul & 16.7 & 9300 & 48 & 45 & 4 & 3 & 166000 \\
\hline 39 & 18-Jul & 15.3 & 5000 & 35 & 60 & 2 & 3 & 156000 \\
\hline 40 & 22-Jul & 16.2 & 5800 & 52 & 38 & 4 & 6 & 195000 \\
\hline \multirow{3}{*}{41} & 24-Jul & 18.9 & 7600 & 44 & 49 & 4 & 3 & 150000 \\
\hline & 02-Aug & 17.9 & 9800 & 50 & 39 & 5 & 6 & 152000 \\
\hline & 04-Aug & 16.2 & 9900 & 50 & 40 & 3 & 7 & 150000 \\
\hline 42 & 24-Jul & 18.6 & 5500 & 41 & 50 & 4 & 5 & 170000 \\
\hline 43 & 24-Jul & 16.6 & 9600 & 68 & 27 & 2 & 3 & 248000 \\
\hline 44 & 28-Jul & 17.5 & 4800 & 25 & 68 & 3 & 4 & 168000 \\
\hline \multirow{13}{*}{45} & 28-Jul & 15 & 5200 & 60 & 33 & 3 & 4 & 150000 \\
\hline & 29-Jul & 15.3 & 5300 & 58 & 34 & 4 & 4 & 150000 \\
\hline & 30-Jul & 16.6 & 10000 & 68 & 24 & 3 & 5 & 176000 \\
\hline & 31-Jul & 15.1 & 8600 & 67 & 23 & 4 & 6 & 231000 \\
\hline & 01-Aug & 15.4 & 10000 & 67 & 24 & 4 & 5 & 239000 \\
\hline & 02-Aug & 15.4 & 11300 & 54 & 37 & 4 & 5 & 200000 \\
\hline & 03-Aug & 15.7 & 12300 & 67 & 28 & 2 & 3 & 331000 \\
\hline & 04-Aug & 14.8 & 10600 & 63 & 30 & 3 & 4 & 278000 \\
\hline & 05-Aug & 14.6 & 8100 & 58 & 31 & 3 & 8 & 249000 \\
\hline & 06-Aug & 14.4 & 7600 & 58 & 32 & 3 & 7 & 297000 \\
\hline & 07-Aug & 14 & 7000 & 50 & 41 & 3 & 6 & 304000 \\
\hline & 08-Aug & 14 & 5800 & 40 & 55 & 3 & 2 & 275000 \\
\hline & 09-Aug & 14.5 & 6500 & 44 & 46 & 3 & 7 & 336000 \\
\hline
\end{tabular}


Study on the Effects of Sars-Cov-2 Infection on the Hematological and Biochemical Parameters and Clinicopathological Correlation in the Evolution of Covid-19

\begin{tabular}{|c|c|c|c|c|c|c|c|c|}
\hline 46 & 29-Jul & 15.2 & 7100 & 44 & 49 & 3 & 4 & 150000 \\
\hline \multirow{2}{*}{47} & 29-Jul & 16.2 & 7700 & 56 & 37 & 4 & 3 & 216000 \\
\hline & 10-Aug & 16 & 5600 & 30 & 64 & 3 & 3 & 150000 \\
\hline 48 & 30-Jul & 14.3 & 4400 & 54 & 35 & 5 & 6 & 204000 \\
\hline 49 & 31-Jul & 15.4 & 6900 & 53 & 40 & 3 & 4 & 254000 \\
\hline 50 & 31-Jul & 13.2 & 7900 & 54 & 36 & 4 & 6 & 236000 \\
\hline 51 & 31-Jul & 17.3 & 3800 & 39 & 50 & 4 & 7 & 186000 \\
\hline 52 & 31-Jul & 16.3 & 6600 & 61 & 33 & 2 & 4 & 267000 \\
\hline \multirow{2}{*}{53} & 31-Jul & 14.6 & 3800 & 49 & 41 & 4 & 6 & 153000 \\
\hline & 06-Aug & 14.4 & 5600 & 54 & 38 & 3 & 5 & 196000 \\
\hline 54 & 01-Aug & 17.2 & 7000 & 40 & 49 & 5 & 6 & 219000 \\
\hline 55 & 01-Aug & 15.8 & 6400 & 42 & 37 & 3 & 18 & 209000 \\
\hline \multirow{2}{*}{56} & 02-Aug & 18.5 & 5400 & 54 & 37 & 4 & 5 & 196000 \\
\hline & 04-Aug & 17.8 & 9200 & 61 & 31 & 3 & 5 & 186000 \\
\hline 57 & 03-Aug & 17.2 & 5800 & 54 & 37 & 3 & 6 & 186000 \\
\hline 58 & 03-Aug & 17.3 & 6700 & 61 & 32 & 3 & 4 & 15000 \\
\hline 59 & 06-Aug & 15.2 & 5900 & 62 & 29 & 3 & 6 & 164000 \\
\hline 60 & 06-Aug & 15 & 4500 & 41 & 52 & 3 & 4 & 150000 \\
\hline 61 & 06-Aug & 12.4 & 4400 & 41 & 52 & 2 & 5 & 150000 \\
\hline 62 & 06-Aug & 15.3 & 6400 & 58 & 34 & 5 & 3 & 150000 \\
\hline 63 & 06-Aug & 14.2 & 5200 & 59 & 35 & 3 & 3 & 150000 \\
\hline \multirow{2}{*}{64} & 06-Aug & 13 & 2400 & 45 & 49 & 4 & 2 & 100000 \\
\hline & 10-Aug & 13 & 3200 & 50 & 45 & 3 & 2 & 150000 \\
\hline 65 & 06-Aug & 15 & 8000 & 66 & 30 & 2 & 2 & 150000 \\
\hline 66 & 07-Aug & 15.3 & 5000 & 43 & 50 & 3 & 4 & 150000 \\
\hline 67 & 07-Aug & 14.7 & 6300 & 65 & 31 & 3 & 1 & 150000 \\
\hline 68 & 07-Aug & 16 & 5300 & 48 & 46 & 2 & 4 & 161000 \\
\hline 69 & 08-Aug & 15.3 & 5000 & 32 & 60 & 2 & 6 & 164000 \\
\hline \multirow{2}{*}{70} & 08-Aug & 16.8 & 5600 & 34 & 60 & 4 & 2 & 167000 \\
\hline & 11-Aug & 16.4 & 5500 & 42 & 50 & 2 & 6 & 185000 \\
\hline 71 & 08-Aug & 15.9 & 4500 & 41 & 47 & 2 & 10 & 167000 \\
\hline 72 & 09-Aug & 16 & 8600 & 56 & 35 & 4 & 5 & 193000 \\
\hline 73 & 09-Aug & 15.7 & 6900 & 35 & 58 & 3 & 4 & 150000 \\
\hline 74 & 09-Aug & 16.1 & 4200 & 38 & 55 & 4 & 3 & 211000 \\
\hline 75 & 09-Aug & 17 & 6700 & 50 & 44 & 4 & 2 & 150000 \\
\hline 76 & 09-Aug & 16.7 & 9300 & 36 & 44 & 4 & 16 & 150000 \\
\hline 77 & 09-Aug & 12.6 & 8500 & 53 & 37 & 3 & 7 & 150000 \\
\hline 78 & 10-Aug & 16.1 & 7900 & 32 & 35 & 3 & 30 & 150000 \\
\hline 79 & 11-Aug & 12.6 & 3600 & 30 & 64 & 2 & 4 & 193000 \\
\hline 80 & 11-Aug & 15 & 5600 & 38 & 53 & 3 & 6 & 150000 \\
\hline 81 & 11-Aug & 14.3 & 4100 & 42 & 50 & 3 & 5 & 164000 \\
\hline 82 & 11-Aug & 16.1 & 5600 & 40 & 50 & 4 & 6 & 251000 \\
\hline 83 & 11-Aug & 15.3 & 6100 & 40 & 52 & 4 & 4 & 182000 \\
\hline
\end{tabular}


Study on the Effects of Sars-Cov-2 Infection on the Hematological and Biochemical Parameters and Clinicopathological Correlation in the Evolution of Covid-19

\begin{tabular}{|c|c|c|c|c|c|c|c|c|}
\hline 84 & 11-Aug & 16.1 & 5600 & 40 & 50 & 4 & 6 & 251000 \\
\hline 85 & 12-Aug & 14.7 & 6600 & 21 & 51 & 3 & 25 & 150000 \\
\hline \multirow{2}{*}{86} & 12-Aug & 15.4 & 8900 & 31 & 37 & 3 & 29 & 157000 \\
\hline & 18-Aug & 15.4 & 11900 & 32 & 43 & 3 & 22 & 221000 \\
\hline 87 & 13-Aug & 16.4 & 4600 & 42 & 50 & 4 & 4 & 150000 \\
\hline 88 & 17-Aug & 16.1 & 5300 & 70 & 20 & 3 & 7 & 168000 \\
\hline 89 & 18-Aug & 15.8 & 7300 & 52 & 39 & 3 & 6 & 158000 \\
\hline 90 & 18-Aug & 15.2 & 5700 & 51 & 42 & 2 & 5 & 150000 \\
\hline 91 & 18-Aug & 16 & 7800 & 58 & 33 & 3 & 6 & 190000 \\
\hline 92 & 18-Aug & 13.9 & 4600 & 54 & 42 & 3 & 1 & 154000 \\
\hline 93 & 19-Aug & 15.1 & 7700 & 49 & 40 & 5 & 6 & 250000 \\
\hline 94 & 19-Aug & 16 & 5900 & 35 & 59 & 4 & 2 & 172000 \\
\hline 95 & 20 Aug 20 & 13.8 & 5500 & 65 & 29 & 3 & 3 & 150000 \\
\hline 96 & 21 Aug 20 & 13 & 4300 & 75 & 18 & 3 & 4 & 153000 \\
\hline 97 & 22 Aug 20 & 15.4 & 6700 & 66 & 23 & 5 & 6 & 185000 \\
\hline 98 & 22 Aug 20 & 16.9 & 6400 & 57 & 34 & 4 & 5 & 150000 \\
\hline 99 & 22 Aug 20 & 13 & 8700 & 85 & 10 & 2 & 3 & 181000 \\
\hline \multirow{2}{*}{100} & 24 Aug 20 & 14.3 & 7700 & 41 & 49 & 4 & 6 & 150000 \\
\hline & 25 Aug 20 & 13.5 & 6700 & 42 & 49 & 3 & 6 & 176000 \\
\hline 101 & 25 Aug 20 & 14.4 & 7300 & 78 & 11 & 5 & 6 & 234000 \\
\hline 102 & 25 Aug 20 & 16.9 & 7700 & 48 & 44 & 4 & 4 & 271000 \\
\hline 103 & 26 Aug 20 & 18 & 7100 & 56 & 35 & 4 & 5 & 230000 \\
\hline 104 & 26 Aug 20 & 14 & 4300 & 52 & 37 & 5 & 6 & 221000 \\
\hline 105 & 26 Aug 20 & 17.8 & 7100 & 52 & 42 & 3 & 3 & 224000 \\
\hline 106 & 26 Aug 20 & 13.7 & 5800 & 40 & 48 & 2 & 10 & 193000 \\
\hline 107 & 26 Aug 20 & 18 & 8600 & 60 & 34 & 2 & 4 & 255000 \\
\hline 108 & 26 Aug 20 & 16 & 3200 & 53 & 42 & 2 & 3 & 189000 \\
\hline 109 & 26 Aug 20 & 16.5 & 6500 & 49 & 40 & 5 & 6 & 237000 \\
\hline 110 & 26 Aug 20 & 16.4 & 5900 & 72 & 17 & 4 & 7 & 266000 \\
\hline 111 & 26 Aug 20 & 16 & 4600 & 34 & 61 & 3 & 2 & 200000 \\
\hline 112 & 26 Aug 20 & 17.6 & 7100 & 56 & 34 & 4 & 6 & 255000 \\
\hline 113 & 26 Aug 20 & 13.7 & 7500 & 63 & 29 & 3 & 5 & 189000 \\
\hline 114 & 26 Aug 20 & 14.5 & 3700 & 39 & 54 & 4 & 3 & 186000 \\
\hline 115 & 26 Aug 20 & 15.8 & 6900 & 43 & 51 & 3 & 3 & 202000 \\
\hline 116 & 26 Aug 20 & 16.7 & 4800 & 32 & 60 & 3 & 5 & 284000 \\
\hline 117 & 26 Aug 20 & 13.7 & 6300 & 51 & 38 & 5 & 6 & 186000 \\
\hline 118 & 27 Aug 20 & 17.2 & 4800 & 55 & 35 & 4 & 6 & 257000 \\
\hline 119 & 27 Aug 20 & 14.8 & 3400 & 60 & 29 & 5 & 6 & 152000 \\
\hline 120 & 28 Aug 20 & 17.7 & 8100 & 38 & 54 & 4 & 4 & 100000 \\
\hline 121 & 28 Aug 20 & 16.4 & 3100 & 21 & 68 & 3 & 8 & 186000 \\
\hline 122 & 28 Aug 20 & 11.9 & 5900 & 57 & 37 & 3 & 3 & 60000 \\
\hline 123 & 28 Aug 20 & 17.2 & 6500 & 58 & 34 & 2 & 6 & 245000 \\
\hline 124 & 28 Aug 20 & 17.2 & 6400 & 30 & 60 & 2 & 8 & 186000 \\
\hline
\end{tabular}


Study on the Effects of Sars-Cov-2 Infection on the Hematological and Biochemical Parameters and Clinicopathological Correlation in the Evolution of Covid-19

\begin{tabular}{|c|c|c|c|c|c|c|c|c|}
\hline 125 & 28 Aug 20 & 13.8 & 3300 & 65 & 28 & 3 & 4 & 179000 \\
\hline 126 & 29 Aug 20 & 13.3 & 6600 & 55 & 37 & 3 & 5 & 345000 \\
\hline 127 & 29 Aug 20 & 15.5 & 2300 & 70 & 28 & 1 & 1 & 186000 \\
\hline 128 & 29 Aug 20 & 14 & 6200 & 60 & 30 & 3 & 7 & 232000 \\
\hline \multirow{2}{*}{129} & 29 Aug 20 & 16.1 & 4000 & 42 & 37 & 4 & 7 & 160000 \\
\hline & 30 Aug 20 & 16.1 & 4100 & 34 & 60 & 3 & 3 & 156000 \\
\hline 130 & 29 Aug 20 & 13.9 & 9600 & 60 & 33 & 2 & 5 & 188000 \\
\hline 131 & 30 Aug 20 & 12.6 & 6300 & 59 & 30 & 5 & 6 & 377000 \\
\hline 132 & 30 Aug 20 & 11.2 & 4600 & 52 & 37 & 5 & 6 & 80000 \\
\hline 133 & 30 Aug 20 & 14.1 & 8600 & 75 & 20 & 2 & 3 & 169000 \\
\hline 134 & 30 Aug 20 & 13.9 & 10500 & 64 & 28 & 3 & 5 & 208000 \\
\hline 135 & 30 Aug 20 & 18.4 & 4400 & 55 & 34 & 5 & 6 & 172000 \\
\hline 136 & 30 Aug 20 & 15.9 & 9700 & 67 & 24 & 4 & 5 & 231000 \\
\hline 137 & 30 Aug 20 & 15.3 & 4900 & 72 & 19 & 4 & 5 & 154000 \\
\hline 138 & 30 Aug 20 & 15.5 & 4500 & 54 & 35 & 5 & 6 & 234000 \\
\hline 139 & 31 Aug 20 & 12.8 & 7200 & 55 & 37 & 3 & 5 & 365000 \\
\hline 140 & 31 Aug 20 & 15.3 & 4500 & 50 & 40 & 4 & 6 & 151000 \\
\hline 141 & 31 Aug 20 & 15.7 & 4600 & 37 & 58 & 3 & 2 & 248000 \\
\hline 142 & 31 Aug 20 & 15.5 & 8700 & 60 & 30 & 3 & 7 & 215000 \\
\hline 143 & 31 Aug 20 & 14.3 & 10900 & 60 & 32 & 2 & 6 & 268000 \\
\hline 144 & 31 Aug 20 & 14.8 & 6700 & 62 & 30 & 3 & 6 & 251000 \\
\hline 145 & 31 Aug 20 & 15.2 & 4600 & 74 & 20 & 2 & 4 & 150000 \\
\hline 146 & 31 Aug 20 & 17.9 & 4000 & 50 & 40 & 3 & 7 & 160000 \\
\hline 147 & 31 Aug 20 & 11.4 & 5200 & 55 & 36 & 4 & 5 & 80000 \\
\hline 148 & 31 Aug 20 & 14.7 & 3300 & 57 & 32 & 5 & 6 & 150000 \\
\hline 149 & 31 Aug 20 & 14.9 & 3800 & 49 & 40 & 5 & 6 & 164000 \\
\hline 150 & 31 Aug 20 & 15.6 & 7700 & 58 & 33 & 4 & 5 & 150000 \\
\hline 151 & 31 Aug 20 & 11 & 4900 & 65 & 20 & 5 & 10 & 150000 \\
\hline 152 & 31 Aug 20 & 13 & 3800 & 50 & 40 & 3 & 7 & 161000 \\
\hline 153 & 31 Aug 20 & 13.2 & 7800 & 55 & 37 & 3 & 5 & 296000 \\
\hline 154 & 31 Aug 20 & 12.2 & 5700 & 65 & 30 & 2 & 3 & 178000 \\
\hline 155 & 31 Aug 20 & 12.5 & 7500 & 32 & 46 & 4 & 18 & 245000 \\
\hline 156 & 01 Sep 20 & 13.7 & 4200 & 62 & 31 & 2 & 5 & 201000 \\
\hline 157 & 01 Sep 20 & 14.7 & 4300 & 39 & 57 & 2 & 2 & 310000 \\
\hline 158 & 01 Sep 20 & 14.8 & 6000 & 62 & 28 & 3 & 7 & 255000 \\
\hline 159 & 01 Sep 20 & 13.3 & 10600 & 60 & 35 & 2 & 3 & 222000 \\
\hline 160 & 01 Sep 20 & 15.2 & 4300 & 53 & 40 & 3 & 4 & 150000 \\
\hline 161 & 01 Sep 20 & 17.3 & 3800 & 40 & 52 & 4 & 4 & 100000 \\
\hline 162 & 01 Sep 20 & 15.6 & 4600 & 40 & 52 & 4 & 4 & 188000 \\
\hline 163 & 01 Sep 20 & 15.9 & 5400 & 39 & 50 & 4 & 7 & 213000 \\
\hline 164 & 01 Sep 20 & 13.1 & 6100 & 54 & 37 & 3 & 6 & 440000 \\
\hline 165 & 01 Sep 20 & 15.7 & 8400 & 55 & 38 & 2 & 5 & 155000 \\
\hline
\end{tabular}


Study on the Effects of Sars-Cov-2 Infection on the Hematological and Biochemical Parameters and Clinicopathological Correlation in the Evolution of Covid-19

\begin{tabular}{|c|c|c|c|c|c|c|c|c|}
\hline 166 & 01 Sep 20 & 14.8 & 2900 & 39 & 50 & 3 & 8 & 150000 \\
\hline 167 & 01 Sep 20 & 14.8 & 3200 & 44 & 44 & 5 & 7 & 216000 \\
\hline 168 & 01 Sep 20 & 14.3 & 8700 & 68 & 23 & 4 & 5 & 158000 \\
\hline 169 & 01 Sep 20 & 15 & 7200 & 65 & 30 & 1 & 4 & 313000 \\
\hline 170 & 02 Sep 20 & 15.3 & 4400 & 38 & 51 & 5 & 6 & 186000 \\
\hline 171 & 02 Sep 20 & 13.1 & 8500 & 50 & 40 & 3 & 7 & 193000 \\
\hline 172 & 02 Sep 20 & 15.1 & 9100 & 70 & 25 & 2 & 3 & 321000 \\
\hline 173 & 02 Sep 20 & 13.5 & 6100 & 38 & 58 & 3 & 1 & 403000 \\
\hline 174 & 02 Sep 20 & 14.9 & 4000 & 53 & 42 & 3 & 2 & 203000 \\
\hline 175 & 02 Sep 20 & 17.1 & 5000 & 60 & 32 & 2 & 6 & 150000 \\
\hline 176 & 02 Sep 20 & 16.6 & 7800 & 70 & 19 & 5 & 6 & 158000 \\
\hline 177 & 02 Sep 20 & 15.7 & 4800 & 35 & 60 & 3 & 2 & 181000 \\
\hline 178 & 02 Sep 20 & 13 & 3200 & 50 & 45 & 3 & 2 & 150000 \\
\hline 179 & 03 Sep 20 & 12.2 & 9000 & 55 & 38 & 3 & 4 & 110000 \\
\hline 180 & 03 Sep 20 & 10.8 & 5700 & 64 & 29 & 3 & 4 & 150000 \\
\hline 181 & 03 Sep 20 & 11.6 & 5000 & 52 & 38 & 2 & 8 & 222000 \\
\hline 182 & 03 Sep 20 & 15 & 9900 & 69 & 23 & 3 & 5 & 344000 \\
\hline 183 & 03 Sep 20 & 15 & 7500 & 50 & 42 & 3 & 5 & 296000 \\
\hline 184 & 03 Sep 20 & 16.4 & 5400 & 54 & 36 & 4 & 6 & 171000 \\
\hline 185 & 03 Sep 20 & 15.1 & 7500 & 52 & 37 & 5 & 6 & 150000 \\
\hline 186 & 04 Sep 20 & 14.5 & 10900 & 71 & 21 & 3 & 5 & 350000 \\
\hline 187 & 04 Sep 20 & 16.9 & 3400 & 68 & 25 & 3 & 4 & 177000 \\
\hline 188 & 04 Sep 20 & 13.6 & 5900 & 60 & 29 & 5 & 6 & 387000 \\
\hline 189 & 04 Sep 20 & 12.6 & 4100 & 50 & 38 & 2 & 10 & 150000 \\
\hline 190 & 04 Sep 20 & 16.7 & 6000 & 34 & 61 & 2 & 3 & 150000 \\
\hline 191 & 04 Sep 20 & 17.6 & 6100 & 40 & 50 & 3 & 7 & 174000 \\
\hline 192 & 04 Sep 20 & 15.8 & 6700 & 56 & 33 & 5 & 6 & 223000 \\
\hline 193 & 04 Sep 20 & 16.8 & 7200 & 38 & 46 & 2 & 14 & 277000 \\
\hline 194 & 04 Sep 20 & 16.2 & 4900 & 38 & 52 & 4 & 6 & 185000 \\
\hline 195 & 04 Sep 20 & 13.7 & 3900 & 30 & 64 & 3 & 3 & 188000 \\
\hline 196 & 04 Sep 20 & 15.2 & 5500 & 41 & 50 & 2 & 7 & 162000 \\
\hline 197 & 04 Sep 20 & 16 & 5700 & 32 & 58 & 3 & 7 & 158000 \\
\hline \multirow{5}{*}{198} & 05 Sep 20 & 15.1 & 10600 & 71 & 22 & 3 & 4 & 424000 \\
\hline & 06 Sep 20 & 15.6 & 9500 & 62 & 30 & 3 & 5 & 380000 \\
\hline & 07 Sep 20 & 15.2 & 9200 & 60 & 33 & 3 & 4 & 438000 \\
\hline & 08 Sep 20 & 15.9 & 10200 & 62 & 33 & 2 & 3 & 443000 \\
\hline & 09 Sep 20 & 15.3 & 9700 & 64 & 29 & 3 & 4 & 385000 \\
\hline \multirow{6}{*}{199} & 06 Sep 20 & 16.4 & 6600 & 73 & 18 & 4 & 5 & 250000 \\
\hline & 07 Sep 20 & 16.2 & 6100 & 69 & 22 & 4 & 5 & 326000 \\
\hline & 08 Sep 20 & 16.9 & 7900 & 66 & 26 & 3 & 5 & 324000 \\
\hline & 09 Sep 20 & 17.6 & 7000 & 67 & 24 & 4 & 5 & 417000 \\
\hline & 11 Sep 20 & 18.3 & 7500 & 52 & 38 & 4 & 6 & 410000 \\
\hline & 05 Sep 20 & 16.5 & 6400 & 75 & 17 & 3 & 5 & 209000 \\
\hline
\end{tabular}


Study on the Effects of Sars-Cov-2 Infection on the Hematological and Biochemical Parameters and Clinicopathological Correlation in the Evolution of Covid-19

\begin{tabular}{|c|c|c|c|c|c|c|c|c|}
\hline 200 & 06 Sep 20 & 16.5 & 5900 & 50 & 39 & 5 & 6 & 205000 \\
\hline 201 & 06 Sep 20 & 14.3 & 7900 & 50 & 36 & 5 & 9 & 174000 \\
\hline 202 & 07 Sep 20 & 14.4 & 4600 & 36 & 52 & 4 & 8 & 162000 \\
\hline 203 & 07 Sep 20 & 13.2 & 6100 & 62 & 27 & 5 & 6 & 206000 \\
\hline 204 & 08 Sep 20 & 15 & 8800 & 50 & 39 & 5 & 6 & 263000 \\
\hline 205 & 08 Sep 20 & 16.5 & 6100 & 40 & 49 & 5 & 6 & 214000 \\
\hline 206 & 08 Sep 20 & 15.3 & 3200 & 42 & 47 & 5 & 6 & 168000 \\
\hline 207 & 08 Sep 20 & 14.9 & 8400 & 54 & 37 & 4 & 5 & 258000 \\
\hline 208 & 08 Sep 20 & 15.1 & 6900 & 52 & 36 & 5 & 7 & 215000 \\
\hline 209 & 08 Sep 20 & 16.6 & 6800 & 50 & 42 & 2 & 6 & 217000 \\
\hline 210 & 08 Sep 20 & 12.8 & 5200 & 43 & 44 & 3 & 10 & 150000 \\
\hline 211 & 08 Sep 20 & 14.7 & 5300 & 34 & 53 & 4 & 9 & 158000 \\
\hline 212 & 09 Sep 20 & 15.1 & 7600 & 52 & 37 & 5 & 6 & 259000 \\
\hline 213 & 09 Sep 20 & 15 & 8100 & 50 & 41 & 4 & 5 & 252000 \\
\hline 214 & 09 Sep 20 & 15.4 & 4500 & 51 & 38 & 5 & 6 & 150000 \\
\hline 215 & 09 Sep 20 & 16.1 & 3800 & 42 & 46 & 5 & 7 & 150000 \\
\hline 216 & 09 Sep 20 & 16.1 & 8100 & 54 & 37 & 4 & 5 & 191000 \\
\hline 217 & 09 Sep 20 & 15 & 6700 & 60 & 31 & 4 & 5 & 181000 \\
\hline 218 & 09 Sep 20 & 15.1 & 4700 & 46 & 45 & 4 & 5 & 162000 \\
\hline 219 & 09 Sep 20 & 13.2 & 4900 & 38 & 51 & 5 & 6 & 159000 \\
\hline 220 & 10 Sep 20 & 14.7 & 8200 & 63 & 32 & 2 & 3 & 346000 \\
\hline 221 & 10 Sep 20 & 14.6 & 13600 & 67 & 24 & 4 & 5 & 322000 \\
\hline 222 & 10 Sep 20 & 15.8 & 4100 & 54 & 34 & 5 & 7 & 157000 \\
\hline 223 & 10 Sep 20 & 16.2 & 15500 & 79 & 17 & 2 & 2 & 281000 \\
\hline 224 & 10 Sep 20 & 16.9 & 6400 & 54 & 34 & 5 & 7 & 222000 \\
\hline \multirow{3}{*}{225} & 10 Sep 20 & 15.4 & 4600 & 46 & 43 & 5 & 6 & 216000 \\
\hline & 11 Sep 20 & 16.2 & 4800 & 40 & 51 & 4 & 5 & 196000 \\
\hline & 14 Sep 20 & 15.7 & 5600 & 45 & 43 & 2 & 10 & 255000 \\
\hline 226 & 11 Sep 20 & 14.5 & 4500 & 60 & 34 & 2 & 4 & 210000 \\
\hline 227 & 11 Sep 20 & 15.1 & 15300 & 80 & 15 & 2 & 3 & 291000 \\
\hline 228 & 11 Sep 20 & 18.3 & 7500 & 52 & 38 & 4 & 6 & 410000 \\
\hline 229 & 11 Sep 20 & 14.5 & 8100 & 62 & 30 & 3 & 5 & 288000 \\
\hline 230 & 11 Sep 20 & 15.1 & 9700 & 50 & 42 & 3 & 5 & 250000 \\
\hline 231 & 11 Sep 20 & 15.3 & 9500 & 68 & 25 & 2 & 5 & 318000 \\
\hline \multirow{2}{*}{232} & 11 Sep 20 & 13 & 5000 & 54 & 37 & 4 & 5 & 221000 \\
\hline & 11 Sep 20 & 12.8 & 9600 & 73 & 22 & 2 & 3 & 184000 \\
\hline 233 & 12 Sep 20 & 16.5 & 9400 & 26 & 46 & 4 & 24 & 238000 \\
\hline 234 & 12 Sep 20 & 13.5 & 6700 & 88 & 10 & 1 & 1 & 200000 \\
\hline 235 & 12 Sep 20 & 14.5 & 9800 & 62 & 29 & 4 & 5 & 239000 \\
\hline 236 & 12 Sep 20 & 15.3 & 13400 & 76 & 19 & 2 & 3 & 284000 \\
\hline 237 & 12 Sep 20 & 16 & 4500 & 50 & 39 & 5 & 6 & 228000 \\
\hline 238 & 12 Sep 20 & 14.3 & 9300 & 62 & 29 & 4 & 5 & 327000 \\
\hline 239 & 12 Sep 20 & 15.9 & 4200 & 50 & 39 & 5 & 6 & 192000 \\
\hline
\end{tabular}


Study on the Effects of Sars-Cov-2 Infection on the Hematological and Biochemical Parameters and Clinicopathological Correlation in the Evolution of Covid-19

\begin{tabular}{|c|c|c|c|c|c|c|c|c|}
\hline 240 & 13 Sep 20 & 13.9 & 7500 & 54 & 35 & 5 & 6 & 212000 \\
\hline 241 & 13 Sep 20 & 13.8 & 7300 & 63 & 28 & 4 & 5 & 351000 \\
\hline 242 & 13 Sep 20 & 16 & 6600 & 54 & 36 & 4 & 6 & 243000 \\
\hline 243 & 13 Sep 20 & 16.1 & 11500 & 49 & 40 & 5 & 6 & 273000 \\
\hline 244 & 13 Sep 20 & 13.2 & 5000 & 60 & 31 & 4 & 5 & 230000 \\
\hline 245 & 13 Sep 20 & 13.9 & 3800 & 44 & 45 & 5 & 6 & 159000 \\
\hline 246 & 13 Sep 20 & 12 & 4300 & 64 & 25 & 5 & 6 & 459000 \\
\hline 247 & 14 Sep 20 & 12.4 & 7700 & 52 & 34 & 5 & 9 & 150000 \\
\hline 248 & 14 Sep 20 & 14.6 & 9000 & 50 & 40 & 3 & 7 & 238000 \\
\hline 249 & 14 Sep 20 & 16.3 & 9900 & 50 & 40 & 4 & 6 & 242000 \\
\hline 250 & 14 Sep 20 & 13.3 & 7000 & 60 & 30 & 3 & 7 & 370000 \\
\hline 251 & 14 Sep 20 & 13.5 & 6000 & 60 & 32 & 3 & 5 & 211000 \\
\hline 252 & 14 Sep 20 & 12 & 7000 & 83 & 15 & 1 & 1 & 150000 \\
\hline 253 & 15 Sep 20 & 13.1 & 6600 & 54 & 35 & 5 & 6 & 443000 \\
\hline 254 & 15 Sep 20 & 15.7 & 5700 & 46 & 45 & 4 & 5 & 254000 \\
\hline 255 & 15 Sep 20 & 16.2 & 9400 & 55 & 34 & 5 & 6 & 268000 \\
\hline 256 & 15 Sep 20 & 14.7 & 6400 & 58 & 33 & 4 & 5 & 237000 \\
\hline 257 & 15 Sep 20 & 12.8 & 6000 & 50 & 40 & 4 & 6 & 247000 \\
\hline 258 & 15 Sep 20 & 16.4 & 12000 & 86 & 8 & 2 & 4 & 328000 \\
\hline 259 & 15 Sep 20 & 15.6 & 5100 & 60 & 32 & 3 & 5 & 174000 \\
\hline 260 & 15 Sep 20 & 13.5 & 7200 & 35 & 58 & 4 & 3 & 262000 \\
\hline 261 & 16 Sep 20 & 13.9 & 10100 & 58 & 31 & 5 & 6 & 447000 \\
\hline 262 & 16 Sep 20 & 14.7 & 5900 & 50 & 39 & 5 & 6 & 237000 \\
\hline 263 & 16 Sep 20 & 15.2 & 7400 & 58 & 33 & 4 & 5 & 216000 \\
\hline 264 & 16 Sep 20 & 15.7 & 10000 & 65 & 26 & 4 & 5 & 288000 \\
\hline 265 & 16 Sep 20 & 13.1 & 8100 & 61 & 29 & 4 & 6 & 237000 \\
\hline 266 & 17 Sep 20 & 13.1 & 8900 & 68 & 25 & 2 & 5 & 250000 \\
\hline 267 & 17 Sep 20 & 13.4 & 15800 & 79 & 14 & 3 & 4 & 538000 \\
\hline 268 & 18 Sep 20 & 15.6 & 4400 & 40 & 50 & 3 & 7 & 170000 \\
\hline 269 & 18 Sep 20 & 13.7 & 5000 & 50 & 40 & 3 & 7 & 152000 \\
\hline 270 & 18 Sep 20 & 13.4 & 14000 & 78 & 26 & 2 & 4 & 510000 \\
\hline \multirow{5}{*}{271} & 17 Sep 20 & 7 & 4700 & 56 & 39 & 2 & 3 & 150000 \\
\hline & 18 Sep 20 & 8.2 & 4900 & 78 & 15 & 2 & 5 & 170000 \\
\hline & 19 Sep 20 & 9.1 & 6300 & 71 & 25 & 2 & 2 & 172000 \\
\hline & 20 Sep 20 & 9.2 & 5500 & 53 & 40 & 2 & 5 & 168000 \\
\hline & 21 Sep 20 & 9.3 & 5800 & 53 & 38 & 4 & 5 & 225000 \\
\hline 272 & 19 Sep 20 & 13 & 9100 & 70 & 25 & 2 & 3 & 165000 \\
\hline 273 & 19 Sep 20 & 13 & 4000 & 50 & 40 & 3 & 7 & 165000 \\
\hline 274 & 20 Sep 20 & 13.3 & 9600 & 40 & 51 & 3 & 6 & 275000 \\
\hline 275 & 20 Sep 20 & 13.6 & 4100 & 40 & 50 & 4 & 6 & 175000 \\
\hline 276 & 20 Sep 20 & 16 & 6600 & 60 & 30 & 4 & 6 & 210000 \\
\hline 277 & 20 Sep 20 & 14.4 & 8500 & 55 & 38 & 2 & 5 & 165000 \\
\hline
\end{tabular}


Study on the Effects of Sars-Cov-2 Infection on the Hematological and Biochemical Parameters and Clinicopathological Correlation in the Evolution of Covid-19

\begin{tabular}{|c|c|c|c|c|c|c|c|c|}
\hline 278 & 20 Sep 20 & 12.4 & 15000 & 75 & 21 & 1 & 3 & 160000 \\
\hline 279 & 21 Sep 20 & 12.8 & 10900 & 83 & 13 & 2 & 2 & 304000 \\
\hline \multirow{8}{*}{280} & 21 Sep 20 & 12.4 & 4000 & 60 & 35 & 2 & 3 & 160000 \\
\hline & 22 Sep 20 & 12.8 & 4000 & 40 & 50 & 3 & 7 & 165000 \\
\hline & 23 Sep 20 & 12.5 & 4500 & 46 & 48 & 3 & 3 & 150000 \\
\hline & 24 Sep 20 & 8.5 & 7200 & 70 & 25 & 2 & 3 & 160000 \\
\hline & 24 Sep 20 & 9.1 & 6700 & 70 & 22 & 4 & 4 & 175000 \\
\hline & 25 Sep 20 & 8.1 & 1700 & 52 & 42 & 3 & 3 & 183000 \\
\hline & 26 Sep 20 & 8.5 & 4900 & 56 & 37 & 4 & 3 & 192000 \\
\hline & 27 Sep 20 & 9.4 & 5000 & 54 & 39 & 3 & 4 & 191000 \\
\hline 281 & 24 Sep 20 & 16 & 4700 & 50 & 45 & 2 & 3 & 182000 \\
\hline 282 & 24 Sep 20 & 16.1 & 8000 & 51 & 40 & 4 & 5 & 152000 \\
\hline 283 & 24 Sep 20 & 16.7 & 6300 & 40 & 49 & 3 & 6 & 180000 \\
\hline 284 & 27 Sep 20 & 15 & 5300 & 54 & 37 & 4 & 5 & 187000 \\
\hline 285 & 27 Sep 20 & 15.4 & 3400 & 54 & 40 & 2 & 4 & 222000 \\
\hline 286 & 27 Sep 20 & 14.4 & 4700 & 49 & 38 & 4 & 9 & 154000 \\
\hline 287 & 28 Sep 20 & 16.2 & 13100 & 35 & 38 & 3 & 24 & 255000 \\
\hline 288 & 28 Sep 20 & 9.7 & 6300 & 56 & 37 & 3 & 4 & 210000 \\
\hline 289 & 29 Sep 20 & 14.4 & 6200 & 52 & 43 & 3 & 2 & 185000 \\
\hline 290 & 29 Sep 20 & 14.8 & 8100 & 48 & 44 & 2 & 6 & 192000 \\
\hline 291 & 29 Sep 20 & 9.4 & 6800 & 62 & 31 & 2 & 5 & 209000 \\
\hline 292 & 29 Sep 20 & 13.1 & 5000 & 55 & 40 & 2 & 3 & 160000 \\
\hline 293 & 29 Sep 20 & 17 & 8800 & 34 & 41 & 3 & 22 & 255000 \\
\hline 294 & 01 Oct 20 & 16.5 & 5000 & 38 & 45 & 4 & 13 & 162000 \\
\hline 295 & 01 Oct 20 & 13.2 & 5700 & 62 & 32 & 3 & 3 & 192000 \\
\hline 296 & 01 Oct 20 & 14.5 & 5600 & 66 & 30 & 2 & 2 & 150000 \\
\hline 297 & 01 Oct 20 & 15 & 6200 & 58 & 36 & 3 & 3 & 189000 \\
\hline 298 & 02 Oct 20 & 14.2 & 4700 & 42 & 50 & 3 & 5 & 150000 \\
\hline 299 & 02 Oct 20 & 12.2 & 4000 & 54 & 42 & 3 & 3 & 180000 \\
\hline 300 & 02 Oct 20 & 15.2 & 7200 & 55 & 38 & 2 & 5 & 152000 \\
\hline 301 & 03 Oct 20 & 13.2 & 4200 & 37 & 55 & 3 & 5 & 229000 \\
\hline 302 & 03 Oct 20 & 16.4 & 4400 & 35 & 58 & 3 & 4 & 352000 \\
\hline 303 & 03 Oct 20 & 15.8 & 6800 & 30 & 55 & 2 & 13 & 29700 \\
\hline 304 & 05 Oct 20 & 13 & 8300 & 64 & 30 & 2 & 4 & 198000 \\
\hline 305 & 05 Oct 20 & 15 & 7000 & 38 & 57 & 2 & 3 & 176000 \\
\hline 306 & 07 Oct 20 & 15.8 & 5500 & 55 & 40 & 3 & 2 & 150000 \\
\hline 307 & 07 Oct 20 & 14.4 & 4500 & 49 & 43 & 3 & 5 & 375000 \\
\hline 308 & 07 Oct 20 & 16.9 & 4700 & 47 & 44 & 3 & 6 & 368000 \\
\hline 309 & 07 Oct 20 & 17 & 16600 & 70 & 22 & 3 & 5 & 238000 \\
\hline 310 & 07 Oct 20 & 20.1 & 9200 & 40 & 48 & 3 & 9 & 250000 \\
\hline 311 & 07 Oct 20 & 17.6 & 5600 & 32 & 58 & 3 & 7 & 202000 \\
\hline 312 & 09 Oct 20 & 13.2 & 4700 & 50 & 44 & 2 & 4 & 246000 \\
\hline
\end{tabular}


Study on the Effects of Sars-Cov-2 Infection on the Hematological and Biochemical Parameters and Clinicopathological Correlation in the Evolution of Covid-19

\begin{tabular}{|c|c|c|c|c|c|c|c|c|}
\hline 313 & 09 Oct 20 & 14.1 & 4400 & 44 & 52 & 2 & 2 & 150000 \\
\hline 314 & 09 Oct 20 & 13.9 & 6300 & 44 & 48 & 4 & 4 & 150000 \\
\hline 315 & 09 Oct 20 & 15.9 & 4900 & 50 & 42 & 3 & 5 & 176000 \\
\hline 316 & 09 Oct 20 & 15.2 & 4900 & 36 & 58 & 2 & 4 & 194000 \\
\hline 317 & 10 Oct 20 & 16.9 & 5400 & 50 & 44 & 2 & 4 & 255000 \\
\hline 318 & 10 Oct 20 & 15.2 & 6700 & 63 & 30 & 3 & 4 & 150000 \\
\hline 319 & 10 Oct 20 & 15.1 & 4500 & 60 & 32 & 3 & 5 & 395000 \\
\hline 320 & 11 Oct 20 & 17.6 & 7000 & 50 & 41 & 3 & 6 & 262000 \\
\hline 321 & 11 Oct 20 & 15.8 & 7800 & 36 & 58 & 3 & 3 & 171000 \\
\hline 322 & 11 Oct 20 & 14.6 & 6500 & 40 & 52 & 3 & 5 & 184000 \\
\hline 323 & 11 Oct 20 & 15.2 & 4000 & 42 & 52 & 2 & 4 & 150000 \\
\hline 324 & 11 Oct 20 & 13.6 & 5600 & 35 & 55 & 3 & 7 & 150000 \\
\hline 325 & 11 Oct 20 & 14.6 & 6700 & 49 & 46 & 3 & 2 & 159000 \\
\hline 326 & 11 Oct 20 & 15.1 & 5300 & 40 & 55 & 3 & 2 & 165000 \\
\hline 327 & 11 Oct 20 & 14.5 & 5400 & 38 & 58 & 2 & 2 & 100000 \\
\hline 328 & 11 Oct 20 & 14.1 & 4400 & 49 & 45 & 3 & 3 & 150000 \\
\hline 329 & 11 Oct 20 & 14.4 & 2600 & 55 & 36 & 2 & 7 & 150000 \\
\hline 330 & 11 Oct 20 & 15.7 & 4300 & 40 & 54 & 3 & 3 & 150000 \\
\hline 331 & 12 Oct 20 & 16.8 & 5600 & 32 & 54 & 4 & 10 & 333000 \\
\hline 332 & 12 Oct 20 & 15.9 & 4700 & 32 & 60 & 3 & 5 & 154000 \\
\hline 333 & 12 Oct 20 & 12.9 & 6300 & 57 & 34 & 3 & 6 & 198000 \\
\hline 334 & 12 Oct 20 & 14.9 & 8600 & 50 & 41 & 3 & 6 & 251000 \\
\hline 335 & 12 Oct 20 & 14.8 & 6900 & 63 & 29 & 2 & 6 & 189000 \\
\hline 336 & 12 Oct 20 & 14.7 & 8700 & 46 & 44 & 4 & 6 & 356000 \\
\hline 337 & 12 Oct 20 & 16.4 & 4800 & 55 & 39 & 2 & 4 & 160000 \\
\hline 338 & 12 Oct 20 & 17.1 & 5600 & 47 & 45 & 3 & 5 & 203000 \\
\hline 339 & 12 Oct 20 & 15.7 & 6700 & 50 & 45 & 2 & 3 & 318000 \\
\hline 340 & 12 Oct 20 & 16.2 & 7100 & 48 & 44 & 2 & 6 & 170000 \\
\hline 341 & 12 Oct 20 & 12.7 & 3800 & 62 & 30 & 3 & 5 & 220000 \\
\hline 342 & 12 Oct 20 & 17 & 7800 & 55 & 37 & 3 & 5 & 259000 \\
\hline 343 & 13 Oct 20 & 13.2 & 6400 & 53 & 42 & 3 & 2 & 150000 \\
\hline 344 & 14 Oct 20 & 14.5 & 7900 & 86 & 10 & 2 & 2 & 150000 \\
\hline 345 & 14 Oct 20 & 14.1 & 5600 & 55 & 35 & 3 & 7 & 169000 \\
\hline 346 & 14 Oct 20 & 15 & 5200 & 55 & 38 & 3 & 4 & 150000 \\
\hline 347 & 14 Oct 20 & 16.6 & 4200 & 39 & 54 & 3 & 4 & 150000 \\
\hline 348 & 14 Oct 20 & 14.9 & 7700 & 35 & 60 & 3 & 2 & 272000 \\
\hline 349 & 14 Oct 20 & 16.8 & 6900 & 48 & 42 & 3 & 7 & 222000 \\
\hline 350 & 14 Oct 20 & 15.2 & 6400 & 40 & 55 & 2 & 3 & 263000 \\
\hline 351 & 14 Oct 20 & 12.5 & 6800 & 55 & 38 & 2 & 5 & 186000 \\
\hline 352 & 14 Oct 20 & 15.5 & 6300 & 38 & 54 & 4 & 4 & 200000 \\
\hline 353 & 14 Oct 20 & 14 & 6300 & 54 & 40 & 2 & 4 & 150000 \\
\hline 354 & 14 Oct 20 & 13.9 & 3400 & 54 & 40 & 4 & 2 & 150000 \\
\hline 355 & 14 Oct 20 & 17.1 & 6200 & 50 & 40 & 3 & 7 & 245000 \\
\hline
\end{tabular}


Study on the Effects of Sars-Cov-2 Infection on the Hematological and Biochemical Parameters and Clinicopathological Correlation in the Evolution of Covid-19

\begin{tabular}{|c|c|c|c|c|c|c|c|c|}
\hline 356 & 14 Oct 20 & 17.6 & 5700 & 50 & 42 & 3 & 5 & 240000 \\
\hline 357 & 14 Oct 20 & 17.2 & 6000 & 51 & 40 & 3 & 6 & 243000 \\
\hline 358 & 15 Oct 20 & 12 & 8100 & 80 & 15 & 3 & 2 & 150000 \\
\hline 359 & 15 Oct 20 & 15.1 & 4000 & 45 & 50 & 2 & 3 & 150000 \\
\hline 360 & 15 Oct 20 & 16.3 & 6000 & 40 & 52 & 4 & 4 & 191000 \\
\hline 361 & 15 Oct 20 & 14.2 & 5600 & 43 & 50 & 2 & 5 & 165000 \\
\hline 362 & 15 Oct 20 & 16.8 & 4100 & 38 & 55 & 4 & 3 & 150000 \\
\hline 363 & 16 Oct 20 & 16.8 & 5600 & 36 & 52 & 2 & 10 & 150000 \\
\hline 364 & 16 Oct 20 & 16.3 & 7500 & 50 & 40 & 3 & 7 & 191000 \\
\hline 365 & 16 Oct 20 & 12.9 & 6800 & 70 & 25 & 3 & 2 & 150000 \\
\hline 366 & 16 Oct 20 & 16.5 & 5700 & 37 & 56 & 2 & 5 & 150000 \\
\hline 367 & 17 Oct 20 & 12.8 & 7100 & 70 & 24 & 2 & 4 & 16500 \\
\hline 368 & 17 Oct 20 & 15.3 & 4200 & 50 & 45 & 3 & 2 & 150000 \\
\hline 369 & 18 Oct 20 & 14.8 & 6100 & 40 & 54 & 3 & 3 & 150000 \\
\hline 370 & 18 Oct 20 & 11.6 & 11900 & 85 & 10 & 2 & 3 & 204000 \\
\hline 371 & 18 Oct 20 & 15.9 & 6300 & 50 & 41 & 3 & 6 & 206000 \\
\hline 372 & 18 Oct 20 & 12.5 & 9500 & 76 & 20 & 2 & 2 & 176000 \\
\hline 373 & 18 Oct 20 & 14.3 & 8600 & 50 & 42 & 3 & 5 & 227000 \\
\hline 374 & 18 Oct 20 & 15.7 & 4000 & 48 & 46 & 2 & 4 & 181000 \\
\hline 375 & 18 Oct 20 & 16.6 & 3200 & 38 & 55 & 4 & 3 & 166000 \\
\hline 376 & 18 Oct 20 & 15.2 & 8200 & 60 & 34 & 2 & 4 & 177000 \\
\hline 377 & 18 Oct 20 & 15 & 7500 & 40 & 53 & 2 & 5 & 220000 \\
\hline 378 & 18 Oct 20 & 13 & 6100 & 55 & 37 & 3 & 5 & 210000 \\
\hline 379 & 18 Oct 20 & 17 & 7100 & 55 & 38 & 2 & 5 & 171000 \\
\hline 380 & 18 Oct 20 & 16.2 & 7600 & 50 & 40 & 4 & 6 & 185000 \\
\hline
\end{tabular}

Table 2: The haematological profile of Covid-19 positive patients admitted in the hospital between Jun 20 and Oct 20.

\begin{tabular}{|c|c|c|c|c|c|c|c|}
\hline SI No & $\begin{array}{c}\text { Date of } \\
\text { Investigation }\end{array}$ & $\begin{array}{c}\text { RBS } \\
\text { (mg/dl) }\end{array}$ & $\begin{array}{l}\text { Urea/Creatinine } \\
\text { (mg/dl) }\end{array}$ & $\begin{array}{c}\text { TC/TG/LDL/HDL } \\
\text { (mg/dl) }\end{array}$ & $\begin{array}{c}\text { Total Bilirubin/ } \\
\text { Direct Bilirubin } \\
\text { (mg/dl) }\end{array}$ & LDH & CRP, PT/APTT/INR \\
\hline \multirow{3}{*}{1} & 20 Jun20 & & $35 / 1.3$ & & $0.8 / 0.5$ & 248 & \\
\hline & 23 Jun20 & & $30 / 1.0$ & $163 / 142 / 96 / 40$ & $0.9 / 0.4$ & 275 & $\begin{array}{c}\text { CRP-NEGATIVE, PT-13/17, } \\
\text { INR-1.30 }\end{array}$ \\
\hline & 28 Jun20 & 79 & $31 / 1.1$ & $169 / 96 / 103 / 46$ & $0.7 / 0.4$ & 264 & $\begin{array}{l}\text { CRP-NEGATIVE, PT - 13/17, } \\
\text { INR-1.32, APTT-30/32 }\end{array}$ \\
\hline \multirow{3}{*}{2} & 21 Jun20 & & $34 / 1.2$ & & $0.8 / 0.5$ & & \\
\hline & 23 Jun20 & & $32 / 1.1$ & & $0.8 / 0.5$ & 279 & CRP- NEGATIVE \\
\hline & 28 Jun20 & 84 & $32 / 1.1$ & $154 / 100 / 90 / 44$ & $0.7 / 0.3$ & 245 & CRP-NEGATIVE \\
\hline 3 & 26 Jun20 & & $32 / 1.1$ & $181 / 163 / 108 / 40$ & $0.9 / 0.5$ & 239 & CRP- NEGATIVE \\
\hline
\end{tabular}


Study on the Effects of Sars-Cov-2 Infection on the Hematological and Biochemical Parameters and Clinicopathological Correlation in the Evolution of Covid-19

\begin{tabular}{|c|c|c|c|c|c|c|c|}
\hline 4 & 27 Jun20 & 92 & $34 / 1.2$ & $172 / 89 / 114 / 40$ & $0.7 / 0.3$ & 220 & \\
\hline 5 & 28 Jun20 & 69 & $33 / 1.1$ & $149 / 79 / 93 / 40$ & $0.6 / 0.3$ & 246 & $\begin{array}{l}\text { CRP- NEGATIVE, PT-13/16, } \\
\text { INR-1.21, APTT-30/32 }\end{array}$ \\
\hline 6 & 28 Jun20 & 80 & $29 / 1.0$ & $223 / 136 / 155 / 40$ & $0.7 / 0.3$ & 325 & $\begin{array}{l}\text { CRP-NEGATIVE, PT-13/15, } \\
\text { INR-1.12, APTT-30/31 }\end{array}$ \\
\hline \multirow{2}{*}{7} & 28 Jun20 & 106 & $34 / 1.2$ & $177 / 110 / 113 / 42$ & $0.6 / 0.2$ & 318 & CRP-NEGATIVE \\
\hline & 29 Jun20 & $91 / 125$ & $32 / 1.1$ & & & & \\
\hline 8 & 29 Jun20 & 95 & $35 / 1.2$ & $175 / 142 / 106 / 40$ & 0.8 & 320 & CRP-NEGATIVE \\
\hline 9 & 29 Jun20 & 101 & $31 / 1.1$ & $149 / 80 / 95 / 38$ & $0.6 / 0.4$ & 306 & CRP-NEGATIVE \\
\hline 10 & 30 Jun20 & 76 & $33 / 1.1$ & $130 / 70 / 80 / 36$ & $0.7 / 0.4$ & 512 & $\begin{array}{l}\text { CRP-NEGATIVE, PT-13/19, } \\
\text { INR-1.42, APTT-30/36 }\end{array}$ \\
\hline 11 & $01 \mathrm{Jul} 20$ & 96 & $28 / 1.0$ & $196 / 92 / 139 / 38$ & $0.7 / 0.3$ & 339 & CRP-NEGATIVE \\
\hline 12 & 01 Jul 20 & 70 & $31 / 1.1$ & $184 / 110 / 121 / 41$ & 0.8 & 425 & CRP- NEGATIVE \\
\hline 13 & $02 \mathrm{Jul} 20$ & 82 & 29/1.1 & $187 / 130 / 120 / 41$ & 0.7 & 328 & CRP- NEGATIVE \\
\hline 14 & $02 \mathrm{Jul} 20$ & 98 & $30 / 1.1$ & $264 / 110 / 206 / 36$ & 0.9 & 315 & CRP- NEGATIVE \\
\hline 15 & $02 \mathrm{Jul} 20$ & 81 & $28 / 1.0$ & $189 / 190 / 117 / 34$ & 0.6 & 310 & CRP- NEGATIVE \\
\hline 16 & $02 \mathrm{Jul} 20$ & 90 & $33 / 1.1$ & $195 / 138 / 126 / 41$ & 0.6 & 227 & CRP- NEGATIVE \\
\hline \multirow{2}{*}{17} & $02 \mathrm{Jul} 20$ & 61 & $31 / 1.1$ & $159 / 70 / 105 / 40$ & 0.7 & 450 & CRP- NEGATIVE \\
\hline & 03 Jul 20 & 78 & $28 / 1.0$ & $139 / 76 / 87 / 36$ & $0.7 / 0.3$ & 470 & \\
\hline 18 & 03 Jul 20 & 84 & $36 / 1.2$ & $191 / 134 / 122 / 42$ & 0.8 & 297 & CRP- NEGATIVE \\
\hline 19 & 03Jul 20 & 62 & $26 / 0.8$ & $191 / 140 / 123 / 40$ & 0.7 & 281 & CRP- NEGATIVE \\
\hline 20 & 03 Jul 20 & 82 & $33 / 1.2$ & $194 / 200 / 118 / 36$ & $0.6 / 0.2$ & 410 & CRP-NEGATIVE \\
\hline \multirow{2}{*}{21} & 03 Jul 20 & 104 & $27 / 1.0$ & $220 / 136 / 154 / 38$ & $0.7 / 0.4$ & 574 & CRP-NEGATIVE \\
\hline & 03 Jul 20 & & & $220 / 136 / 154 / 38$ & & & \\
\hline \multirow{3}{*}{22} & 04 Jul 20 & 95 & $27 / 0.9$ & $149 / 150 / 83 / 36$ & $08 / 0.3$ & 342 & CRP- NEGATIVE \\
\hline & 13 Jul 20 & & $32 / 1.1$ & & $0.7 / 0.3$ & & \\
\hline & $14 \mathrm{Jul} 20$ & & & & & 466 & CRP- NEGATIVE \\
\hline 23 & $05 \mathrm{Jul} 20$ & 59 & $32 / 1.2$ & $194 / 130 / 128 / 40$ & $2.1 / 1.1$ & 236 & CRP- NEGATIVE \\
\hline 24 & $05 \mathrm{Jul} 20$ & 78 & $34 / 1.2$ & $197 / 138 / 131 / 38$ & $0.9 / 0.4$ & 390 & CRP-NEGATIVE \\
\hline 25 & & & & & & & \\
\hline
\end{tabular}


Study on the Effects of Sars-Cov-2 Infection on the Hematological and Biochemical Parameters and Clinicopathological Correlation in the Evolution of Covid-19

\begin{tabular}{|c|c|c|c|c|c|c|c|}
\hline & 07 Jul 20 & 72 & $33 / 1.2$ & $192 / 136 / 124 / 41$ & $0.9 / 0.4$ & 342 & CRP-NEGATIVE \\
\hline \multirow{3}{*}{26} & $15 \mathrm{Jul} 20$ & & $28 / 0.9$ & & $0.8 / 0.3$ & 518 & CRP-NEGATIVE \\
\hline & 17 Jul 20 & 62 & $31 / 1.1$ & $130 / 82 / 75 / 38$ & $0.6 / 0.2$ & 517 & \\
\hline & 18 Jul 20 & & $29 / 1.1$ & & & & CRP-POSITIVE \\
\hline 27 & 07 Jul 20 & 65 & $37 / 1.3$ & $202 / 118 / 136 / 42$ & $0.8 / 0.3$ & 404 & CRP-NEGATIVE \\
\hline 28 & 07 Jul 20 & 68 & $26 / 0.8$ & $186 / 138 / 116 / 42$ & $0.9 / 0.4$ & 386 & CRP-NEGATIVE \\
\hline 29 & 07 Jul 20 & 76 & $30 / 1.1$ & $176 / 110 / 116 / 38$ & $0.8 / 0.4$ & 462 & CRP-NEGATIVE \\
\hline 29 & 08 Jul 20 & & & & & & \\
\hline 30 & 09 Jul 20 & 100 & $31 / 1.1$ & $247 / 110 / 189 / 36$ & $4.1 / 1.9$ & 370 & CRP -NEGATIVE, \\
\hline \multirow{3}{*}{31} & 13 Jul 20 & & $32 / 1.1$ & & $0.7 / 0.3$ & & \\
\hline & 14 Jul 20 & & & & & 466 & CRP-NEGATIVE \\
\hline & 15 Jul 20 & & $29 / 1.0$ & & $0.7 / 0.3$ & 433 & CRP-NEGATIVE \\
\hline 32 & 14 Jul 20 & 67 & $32 / 1.2$ & $156 / 90 / 94 / 44$ & $0.6 / 0.2$ & 346 & CRP-NEGATIVE \\
\hline \multirow{2}{*}{33} & 14 Jul 20 & 69 & $29 / 1.0$ & $188 / 110 / 124 / 42$ & $0.8 / 0.3$ & 356 & CRP-NEGATIVE \\
\hline & $15 \mathrm{Jul} 20$ & 74 & $36 / 1.3$ & $159 / 90 / 101 / 40$ & $1.3 / 0.7$ & & \\
\hline \multirow{2}{*}{34} & 14 Jul 20 & 64 & $31 / 1.2$ & $197 / 130 / 131 / 40$ & $0.9 / 0.4$ & 390 & CRP-NEGATIVE \\
\hline & 16 Jul 20 & 69 & $32 / 1.2$ & $198 / 128 / 130 / 42$ & $0.8 / 0.3$ & 334 & CRP-NEGATIVE \\
\hline 35 & 15 Jul 20 & & $33 / 1.2$ & & $0.8 / 0.4$ & 405 & CRP-NEGATIVE \\
\hline \multirow{2}{*}{36} & 14 Jul 20 & 62 & $36 / 1.2$ & $236 / 150 / 168 / 38$ & $0.8 / 0.4$ & 401 & CRP-NEGATIVE \\
\hline & $18 \mathrm{Jul} 20$ & 84 & $30 / 1.1$ & $224 / 160 / 156 / 36$ & $0.7 / 0.3$ & 272 & CRP-NEGATIVE \\
\hline 37 & $18 \mathrm{Jul} 20$ & 78 & $31 / 1.1$ & $169 / 140 / 101 / 40$ & $0.8 / 0.4$ & 417 & CRP-NEGATIVE \\
\hline 38 & 18 Jul 20 & 64 & $34 / 1.2$ & $176 / 132 / 109 / 40$ & $0.7 / 0.3$ & 340 & CRP-NEGATIVE \\
\hline 39 & 22 Jul 20 & 68 & $34 / 1.3$ & $163 / 116 / 99 / 40$ & $0.8 / 0.3$ & & CRP-NEGATIVE \\
\hline 40 & 24 Jul 20 & 78 & $24 / 0.8$ & $163 / 98 / 103 / 40$ & $1.0 / 0.3$ & & CRP-NEGATIVE \\
\hline 41 & 24 Jul 20 & 76 & $32 / 1.1$ & $138 / 120 / 73 / 42$ & $0.8 / 0.3$ & & CRP-NEGATIVE \\
\hline 42 & 24 Jul 20 & 92 & $23 / 1.0$ & $175 / 181 / 100 / 38$ & $0.7 / 0.4$ & & CRP-NEGATIVE \\
\hline
\end{tabular}


Study on the Effects of Sars-Cov-2 Infection on the Hematological and Biochemical Parameters and Clinicopathological Correlation in the Evolution of Covid-19

\begin{tabular}{|c|c|c|c|c|c|c|}
\hline 43 & $28 \mathrm{Jul} 20$ & 78 & $31 / 1.1$ & $179 / 130 / 111 / 42$ & $1.0 / 0.4$ & CRP-NEGATIVE \\
\hline 44 & 28 Jul 20 & 102 & $27 / 0.9$ & $134 / 96 / 74 / 40$ & $0.7 / .04$ & CRP-POSITIVE \\
\hline 45 & 29 Jul 20 & 84 & $29 / 1.0$ & $199 / 134 / 132 / 40$ & $0.7 / 0.3$ & CRP-NEGATIVE \\
\hline \multirow{2}{*}{46} & 29 Jul 20 & 140 & $34 / 1.3$ & $278 / 498 / 144 / 34$ & $0.6 / 0.2$ & CRP-NEGATIVE \\
\hline & 31 Jul 20 & 69 & $31 / 1.2$ & $228 / 138 / 163 / 37$ & $0.9 / 0.4$ & \\
\hline 47 & 30 Jul 20 & 78 & $35 / 1.2$ & $140 / 110 / 78 / 40$ & $0.7 / 0.3$ & CRP-NEGATIVE \\
\hline 48 & 31 Jul 20 & 83 & $30 / 0.9$ & $180 / 94 / 123 / 38$ & $0.8 / 0.3$ & CRP-NEGATIVE \\
\hline 49 & 31 Jul 20 & 72 & $32 / 1.0$ & $182 / 146 / 115 / 37$ & $1.0 / 0.4$ & CRP-NEGATIVE \\
\hline 50 & $31 \mathrm{Jul} 20$ & 82 & $34 / 1.0$ & $178 / 134 / 111 / 40$ & $0.8 / 0.3$ & CRP-NEGATIVE \\
\hline 51 & 31 Jul 20 & 92 & $29 / 0.9$ & $225 / 174 / 150 / 40$ & $0.7 / 0.3$ & CRP-NEGATIVE \\
\hline 52 & 31 Jul 20 & 74 & $34 / 1.0$ & $195 / 143 / 126 / 40$ & $0.9 / 0.4$ & CRP-NEGATIVE \\
\hline 53 & 01 Aug 20 & 81 & $29 / 1.1$ & $172 / 120 / 106 / 42$ & $0.7 / 0.3$ & CRP-NEGATIVE \\
\hline 54 & 01 Aug 20 & 86 & $34 / 1.2$ & $200 / 140 / 134 / 38$ & $0.9 / 0.4$ & CRP-NEGATIVE \\
\hline 55 & 03 Aug 20 & 83 & $31 / 1.2$ & $188 / 150 / 120 / 38$ & $0.6 / 0.2$ & \\
\hline 56 & 03 Aug 20 & 72 & $34 / 1.3$ & $174 / 110 / 114 / 38$ & $0.5 / 0.2$ & \\
\hline 57 & 06 Aug 20 & 76 & $31 / 1.0$ & $199 / 198 / 125 / 34$ & $0.8 / 0.3$ & CRP-NEGATIVE \\
\hline 58 & 06 Aug 20 & 76 & $36 / 1.3$ & $148 / 110 / 90 / 36$ & $0.7 / 0.3$ & CRP-NEGATIVE \\
\hline 59 & 06 Aug 20 & 70 & $33 / 1.1$ & $150 / 160 / 80 / 38$ & $0.6 / 0.3$ & CRP-NEGATIVE \\
\hline 60 & 06 Aug 20 & 74 & $32 / 1.2$ & $200 / 135 / 133 / 40$ & $0.6 / 0.2$ & CRP-NEGATIVE \\
\hline 61 & 06 Aug 20 & 100 & $36 / 1.3$ & $176 / 110 / 112 / 42$ & $0.8 / 0.3$ & CRP-NEGATIVE \\
\hline 62 & 06 Aug 20 & 69 & $32 / 1.3$ & $134 / 90 / 76 / 40$ & $0.8 / 0.4$ & CRP-NEGATIVE \\
\hline 63 & 06 Aug 20 & 64 & $34 / 1.3$ & $178 / 200 / 104 / 34$ & $0.6 / 0.2$ & CRP-NEGATIVE \\
\hline 64 & 07 Aug 20 & 62 & $29 / 1.0$ & $177 / 150 / 109 / 38$ & $1.5 / 0.7$ & CRP-NEGATIVE \\
\hline 65 & 07 Aug 20 & 64 & $34 / 1.2$ & $194 / 150 / 128 / 36$ & $0.8 / 0.3$ & CRP-NEGATIVE \\
\hline
\end{tabular}


Study on the Effects of Sars-Cov-2 Infection on the Hematological and Biochemical Parameters and Clinicopathological Correlation in the Evolution of Covid-19

\begin{tabular}{|c|c|c|c|c|c|c|c|}
\hline 68 & 08 Aug 20 & 74 & $36 / 1.3$ & $159 / 90 / 101 / 40$ & $1.3 / 0.7$ & & CRP-NEGATIVE \\
\hline 69 & 08 Aug 20 & 62 & $29 / 1.1$ & $174 / 100 / 120 / 34$ & $0.8 / 0.3$ & & CRP-NEGATIVE \\
\hline 70 & 08 Aug 20 & 62 & $34 / 1.3$ & $223 / 140 / 155 / 40$ & $0.6 / 0.2$ & & CRP-NEGATIVE \\
\hline 72 & 09 Aug 20 & 78 & $29 / 1.0$ & $200 / 126 / 136 / 38$ & $0.7 / 0.3$ & & CRP-NEGATIVE \\
\hline 73 & 09 Aug 20 & 100 & $30 / 1.1$ & $160 / 92 / 102 / 39$ & $0.8 / 0.3$ & & CRP-NEGATIVE \\
\hline 74 & 09 Aug 20 & 105 & $32 / 1.0$ & $189 / 114 / 129 / 37$ & $0.9 / 0.4$ & & CRP-NEGATIVE \\
\hline 77 & 09 Aug 20 & 61 & $34 / 1.2$ & $194 / 90 / 139 / 37$ & $1.4 / 0.8$ & & CRP-NEGATIVE \\
\hline 78 & 10 Aug 20 & 69 & $31 / 1.2$ & $228 / 138 / 163 / 37$ & $0.9 / 0.4$ & & CRP-NEGATIVE \\
\hline 79 & 10 Aug 20 & 62 & $29 / 1.1$ & $182 / 128 / 117 / 39$ & $1.2 / 0.7$ & & CRP-NEGATIVE \\
\hline 80 & 11 Aug 20 & 65 & $28 / 1.0$ & $129 / 78 / 68 / 35$ & $0.8 / 0.3$ & & CRP-NEGATIVE \\
\hline 81 & 11 Aug 20 & 69 & $32 / 1.2$ & $136 / 90 / 83 / 35$ & $0.7 / 0.3$ & & CRP-NEGATIVE \\
\hline 82 & 11 Aug 20 & 68 & $36 / 1.3$ & $165 / 100 / 109 / 36$ & $0.7 / 0.3$ & & CRP-NEGATIVE \\
\hline 88 & 18-Aug & 86 & $31 / 1.2$ & $168 / 100 / 109 / 39$ & $0.7 / 0.3$ & & CRP-POSITIVE \\
\hline 89 & 18-Aug & 79 & $27 / 1.0$ & $191 / 175 / 120 / 36$ & $0.9 / 0.4$ & & CRP-NEGATIVE \\
\hline 90 & 18-Aug & 77 & $26 / 0.9$ & $176 / 99 / 118 / 38$ & $0.8 / 0.3$ & & CRP-NEGATIVE \\
\hline 91 & 19-Aug & 91 & $29 / 1.1$ & $192 / 132 / 126 / 39$ & $1.0 / 0.5$ & & CRP-NEGATIVE \\
\hline 92 & 19-Aug & 82 & $27 / 1.0$ & $176 / 140 / 108 / 40$ & $0.8 / 0.2$ & & CRP-NEGATIVE \\
\hline 93 & 01-Oct & 94 & 29/1.1 & $161 / 98 / 110 / 35$ & 0.8 & 245 & CRP-NEGATIVE \\
\hline 94 & $01-0 c t$ & 92 & $30 / 1.2$ & $136 / 103 / 78 / 35$ & 0.8 & 355 & CRP-POSITIVE \\
\hline 95 & & 89 & $29 / 1.2$ & $156 / 201 / 77 / 38$ & 0.8 & 288 & CRP-NEGATIVE \\
\hline
\end{tabular}


Study on the Effects of Sars-Cov-2 Infection on the Hematological and Biochemical Parameters and Clinicopathological Correlation in the Evolution of Covid-19

\begin{tabular}{|c|c|c|c|c|c|c|c|}
\hline 96 & 01-Oct & 94 & $30 / 1.2$ & $126 / 98 / 71 / 35$ & 0.7 & 276 & CRP-NEGATIVE \\
\hline 97 & & 92 & 28/0.9 & $186 / 139 / 118 / 40$ & 0.8 & 237 & CRP-NEGATIVE \\
\hline 100 & 03-Oct & 91 & $27 / 0.9$ & $189 / 156 / 119 / 38$ & 0.8 & 288 & CRP-NEGATIVE \\
\hline 101 & 03-0ct & 81 & 29/0.8 & $172 / 139 / 106 / 38$ & 0.8 & 302 & CRP-NEGATIVE, \\
\hline 103 & 05-Oct & 106 & $30 / 1.2$ & $129 / 102 / 73 / 35$ & 0.8 & 298 & CRP-NEGATIVE \\
\hline 104 & 07-0ct & 83 & $30 / 1.2$ & $148 / 112 / 90 / 35$ & 0.8 & 434 & CRP-NEGATIVE \\
\hline 105 & 07-Oct & 90 & $28 / 0.9$ & $165 / 135 / 103 / 35$ & 0.8 & 382 & CRP-NEGATIVE \\
\hline 106 & 07-Oct & 102 & $25 / 0.8$ & & 0.9 & 310 & CRP-NEGATIVE \\
\hline 109 & 09-0ct & 92 & $29 / 1.0$ & $163 / 125 / 103 / 35$ & 0.8 & 298 & CRP-POSITIVE \\
\hline 110 & 09-Oct & 95 & $28 / 0.9$ & $175 / 142 / 110 / 36$ & 0.9 & 302 & CRP-NEGATIVE \\
\hline 111 & 09-0ct & 101 & $30 / 1.0$ & $166 / 139 / 100 / 38$ & 0.8 & 325 & CRP-NEGATIVE \\
\hline 112 & 09-Oct & 85 & $29 / 1.0$ & $158 / 142 / 91 / 38$ & 0.8 & 310 & CRP-NEGATIVE \\
\hline 113 & 09-0ct & 98 & $25 / 0.8$ & $175 / 145109 / 36$ & 0.8 & 295 & CRP-NEGATIVE \\
\hline 118 & 11-Oct & 89 & $30 / 1.1$ & $177 / 130 / 113 / 38$ & 0.8 & 301 & CRP-NEGATIVE \\
\hline 119 & $11-0 \mathrm{ct}$ & 88 & $28 / 0.9$ & $163 / 129 / 100 / 37$ & 0.8 & 325 & CRP-NEGATIVE \\
\hline 120 & $11-0 c t$ & 93 & $28 / 0.9$ & $188 / 163 / 115 / 40$ & 0.8 & 296 & CRP-NEGATIVE \\
\hline 126 & $11-0 c t$ & 92 & $28 / 0.9$ & $172 / 137 / 104 / 40$ & 0.8 & 310 & CRP-NEGATIVE \\
\hline 127 & $11-0 c t$ & 95 & $28 / / 1.0$ & $174 / 128 / 112 / 36$ & 0.7 & 302 & CRP NEGATIVE \\
\hline 128 & $12-0 c t$ & 90 & $24 / 0.7$ & $158 / 132 / 96 / 36$ & 0.8 & 310 & CRP-NEGATIVE \\
\hline 129 & $12-0 c t$ & 88 & $30 / 1.0$ & $158 / 126 / 96 / 36$ & 0.8 & 318 & CRP-NEGATIVE \\
\hline 130 & $12-0 c t$ & 92 & $28 / 0.9$ & 188/151/119/38 & 0.8 & 275 & CRP-NEGATIVE \\
\hline 131 & 12-Oct & 85 & $25 / 0.8$ & $162 / 137 / 94 / 40$ & 0.8 & 336 & CRP-NEGATIVE \\
\hline 132 & $12-0 c t$ & 75 & $24 / 0.8$ & $162 / 126 / 94 / 35$ & 0.9 & 302 & CRP-NEGATIVE \\
\hline 133 & $12-0 c t$ & 92 & $28 / 0.9$ & $165 / 131 / 98 / 40$ & 0.8 & 325 & CRP-NEGATIVE \\
\hline 134 & $12-0 c t$ & 91 & $28 / 0.9$ & $148 / 130 / 82 / 40$ & 0.8 & 198 & CRP-NEGATIVE \\
\hline 135 & 12-Oct & 78 & $30 / 1.0$ & $160 / 128 / 99 / 35$ & 0.9 & 309 & CRP-NEGATIVE \\
\hline 136 & $12-0 c t$ & 91 & $28 / 0.9$ & $188 / 161 / 115 / 40$ & 0.8 & 302 & CRP-NEGATIVE \\
\hline 137 & $12-0 c t$ & 88 & $25 / 0.8$ & $172 / 136 / 104 / 40$ & 0.7 & 302 & CRP-NEGATIVE \\
\hline
\end{tabular}


Study on the Effects of Sars-Cov-2 Infection on the Hematological and Biochemical Parameters and Clinicopathological Correlation in the Evolution of Covid-19

\begin{tabular}{|c|c|c|c|c|c|c|c|}
\hline 138 & $12-0 c t$ & 86 & $29 / 1.0$ & $162 / 118 / 103 / 35$ & 0.8 & 307 & CRP-NEGATIVE \\
\hline 139 & $14-0 c t$ & 86 & $31 / 1.2$ & $172 / 139 / 109 / 35$ & 0.8 & 302 & CRP-NEGATIVE \\
\hline 141 & $14-0 c t$ & 92 & $28 / 0.9$ & $186 / 142 / 121 / 36$ & 0.8 & 198 & CRP-NEGATIVE \\
\hline 142 & 14-Oct & 90 & $25 / 0.8$ & $165 / 137 / 99 / 38$ & 0.8 & 301 & CRP-NEGATIVE \\
\hline 144 & $14-0 \mathrm{ct}$ & 97 & $26 / 0.8$ & $165 / 142 / 101 / 35$ & 0.9 & 302 & CRP-NEGATIVE \\
\hline 145 & 14-Oct & 91 & $35 / 1.2$ & $175 / 139 / 103 / 40$ & 0.8 & 302 & CRP-NEGATIVE \\
\hline 146 & $14-0 c t$ & 81 & $24 / 0.8$ & $155 / 131 / 96 / 35$ & 0.8 & 302 & CRP-NEGATIVE \\
\hline 147 & 14-Oct & 91 & $28 / 1.0$ & $169 / 126 / 107 / 36$ & 0.8 & 275 & CRP-NEGATIVE \\
\hline 151 & $14-0 \mathrm{ct}$ & 81 & $28 / 0.9$ & $171 / 139 / 108 / 35$ & 0.8 & 216 & CRP-NEGATIVE \\
\hline 152 & $14-0 c t$ & 80 & $24 / 0.7$ & $162 / 136 / 100 / 36$ & 0.8 & 274 & CRP-NEGATIVE \\
\hline 153 & $15-0 c t$ & & $28 / 0.9$ & $183 / 142 / 114 / 40$ & 0.8 & 312 & CRP-NEGATIVE \\
\hline 154 & $15-0 c t$ & 89 & $25 / 0.8$ & $149 / 120 / 87 / 38$ & 0.7 & 275 & CRP-NEGATIVE \\
\hline 155 & $15-0 c t$ & 79 & $29 / 1.0$ & $163 / 130 / 101 / 36$ & 0.8 & 303 & CRP-NEGATIVE \\
\hline 156 & $15-0 c t$ & 88 & $28 / 0.9$ & $172 / 39 / 109 / 35$ & 0.8 & 236 & CRP-NEGATIVE \\
\hline 157 & $15-0 c t$ & 83 & $29 / 1.0$ & $166 / 142 / 99 / 38$ & 0.9 & 321 & CRP-NEGATIVE \\
\hline 158 & $16-0 c t$ & 90 & $27 / 0.9$ & $176 / 135 / 113 / 36$ & 0.8 & 265 & CRP-NEGATIVE \\
\hline 167 & $18-0 c t$ & 86 & $28 / 0.9$ & $139 / 126 / 78 / 35$ & 0.9 & 307 & CRP-NEGATIVE \\
\hline 168 & $18-0 \mathrm{ct}$ & 92 & $27 / 1.0$ & $186 / 139 / 120 / 38$ & 0.8 & 276 & CRP-NEGATIVE \\
\hline 169 & $18-0 c t$ & 88 & $28 / 0.9$ & $156 / 139 / 88 / 40$ & 0.8 & 263 & CRP-NEGATIVE \\
\hline 170 & $18-0 c t$ & 92 & $29 / 1.0$ & & 0.8 & 226 & CRP-NEGATIVE \\
\hline 171 & $18-0 \mathrm{ct}$ & 89 & $31 / 1.2$ & & 0.8 & 296 & \\
\hline 172 & $18-0 c t$ & 92 & $30 / 1.0$ & & 0.8 & 216 & \\
\hline
\end{tabular}

Table 3: The biochemical profile of Covid-19 positive patients admitted in the hospital between Jun 20 and Oct 20.

Abbreviations: RBS: Random Blood Sugar; TC: Total Cholesterol; TG: Triglycerides; LDL: Low Density Lipoproteins; HDL: High Density Lipoproteins; LDH: Lactate Dehydrogenase; CRP: C-Reactive Protein; PT: Prothrombin Time; APTT: Activated Thromboplastin Time; INR: International Normalized Ratio. 
Study on the Effects of Sars-Cov-2 Infection on the Hematological and Biochemical Parameters and Clinicopathological Correlation in the Evolution of Covid-19

\section{Results}

The Complete Blood Count (CBC) of the Covid-19 patients revealed normal Total Leukocyte Count (TLC) in more than $90 \%$ of patients, Leukocytopenia in less than $5 \%$ of patients, Leukocytosis in about $05 \%$ of cases and Thrombocytopenia in $5 \%$ of cases. It is pertinent to note that majority of the patients, particularly those presenting early in the course of the disease as pre-symptomatic illness, initially presented with Relative Lymphocytosis on days 2 to 3 post sampling that yielded a positive result for Covid-19 with Differential Leukocyte Count (DLC) of lymphocytes being 45 to $55 \%$ (52\% on average) and Total Leucocyte Count (TLC) of 3,500 - 4,200/cmm. The TLC started declining on days 4 to 5 reaching a nadir around day 6 with predominance of neutrophils due to lymphopenia in actuality. The TLC normalized by day 8 either with symptomatic improvement, which was observed with majority of our sample population or with worsening of symptoms. $04 \%$ of the sample population showed increase in TLC which reached the maximum of $16,000 / \mathrm{cmm}$. Such patients also showed presence of other inflammatory markers such as positivity for C-Reactive protein (CRP).

The Peripheral Blood Smear (PBS) confirmed the initial Relative Lymphocytosis in days 2 to 3 post sampling that yielded a positive result for Covid-19 with presence of characteristic Covicytes. The latter are activated T-lymphocytes which are further classified as Downey type I, type II and type-III depending on blastoid, monocytoid and plasmacytoid morphology. These Covicytes exhibit nucleomegaly, round to oval to lobulated sometimes eccentric nuclei, irregular nuclear contours, coarsely granular chromatin and abundant basophilic cytoplasm. The large blastoid Covicytes have basophilic cytoplasm with nuclei showing multiple prominent nucleoli which are rimmed by condensed chromatin. Some cells show cytoplasmic vacuolations. Bizarre nuclear shapes and irregular chromatin distribution were also encountered. However, there was overall increase in cell size with no increase in nuclear cytoplasmic ratio. A few Covicytes revealed amphophilic cytoplasmic granules. The number of Covicytes gradually increased with the disease progression and correlated with their symptomatology. The proportion and pleomorphism increased with severity of the symptoms. The Covicytes diminished in number by days 9 to 10 post sampling while a few still persisted following testing negative for Covid-19. Large granular lymphocytes with oblong eccentric nuclei, coarsely granular chromatic and abundant cytoplasm with heterogenous azurophlic granules were also noted.

The Peripheral Blood Smear examination also revealed presence of Acquired Pelger Huet Anomaly (APHA) in majority of the pa- tients. These pelgeroid neutrophils demonstrate hypolobated nuclei with two lobed nuclei connected by a thin strand of chromatin. Review of outpatient medications revealed no definite evidence of medications reported to be associated with APHA. Inpatient medications were also not pertinent as the peripheral blood studied were drawn during hospital admission before the initiation of any treatment. Occasional neutrophils showing prominent apoptotic changes were also noted. It was also noted that the proportion of these neutrophils with APHA increased with disease progression and diminished as the patients recovered from the illness.

The Platelet Counts too showed changes with gradual decline in the count reaching a nadir between days 3 and 4. However, overt thrombocytopenia with a platelet count of $1,00,000 / \mathrm{cmm}$ was noted in only 04 of our patients. Peripheral blood smear revealed presence of adequate number of platelets in most cases with scattered platelet clumps. However, there was platelet anisocytosis which grew markedly as the disease progressed exhibiting maximum between days 5 and 6 post sampling correlating with a minimum platelet count of $1,00,000 / \mathrm{cmm}$ on smears. Megathrombocytes were noted whose numbers increased between days 6 and 7 post sampling.

The markers of inflammation namely C-reactive protein (CRP) and Lactate dehydrogenase (LDH) were also studied amongst the study population and they correlated well with severity of disease. The CRP was assessed qualitatively while LDH assessment was quantitative with definite serological values. CRP positivity and high values of LDH were documented with patients with moderate symptomatology, elderly age group and those with other comorbidities such as Diabetes mellitus, Hypertension, Obesity, etc.

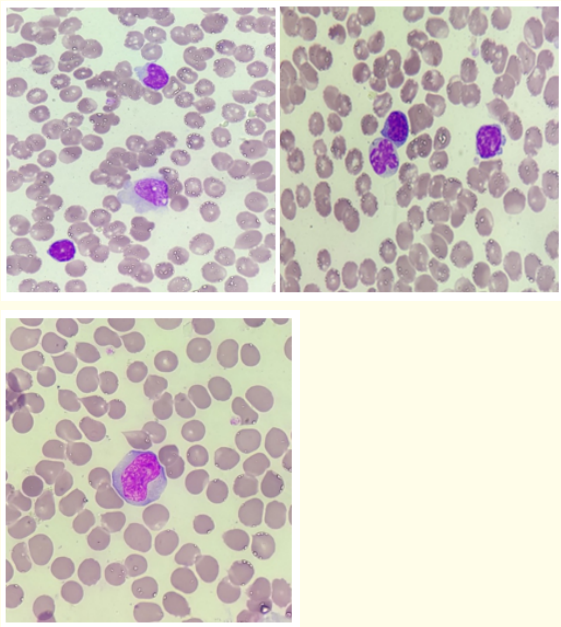

Figure 1: Activated lymphocytes (Covicytes) exhibiting blastoid and monocytoid morphology. 

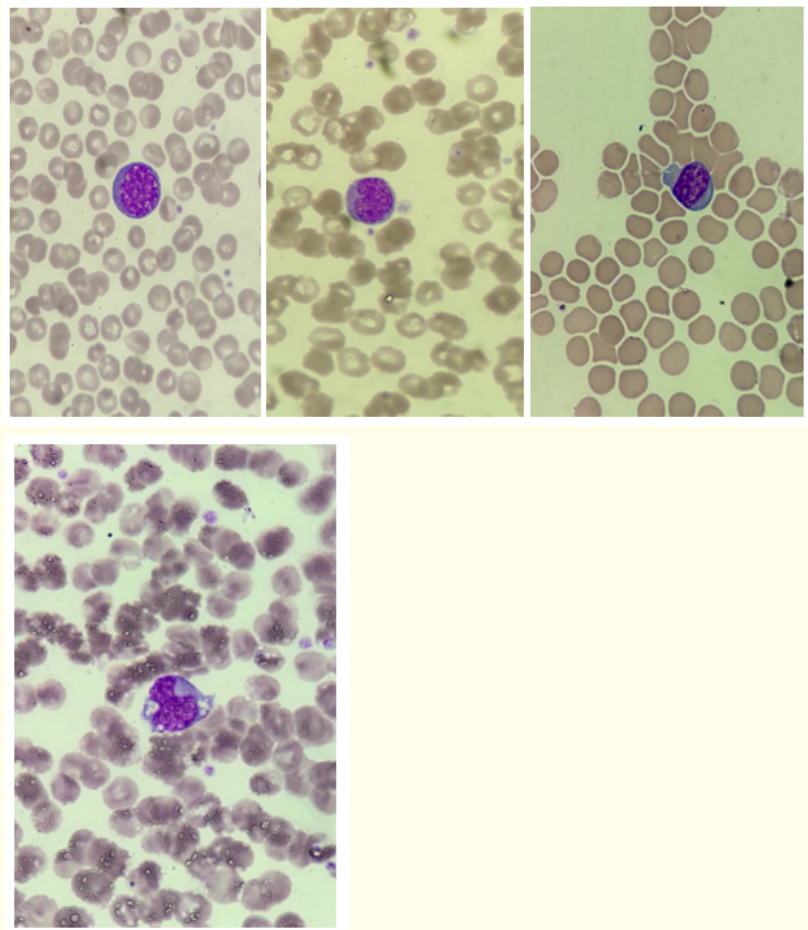

Figure 2: Covicytes exhibiting Blastoid morphology.
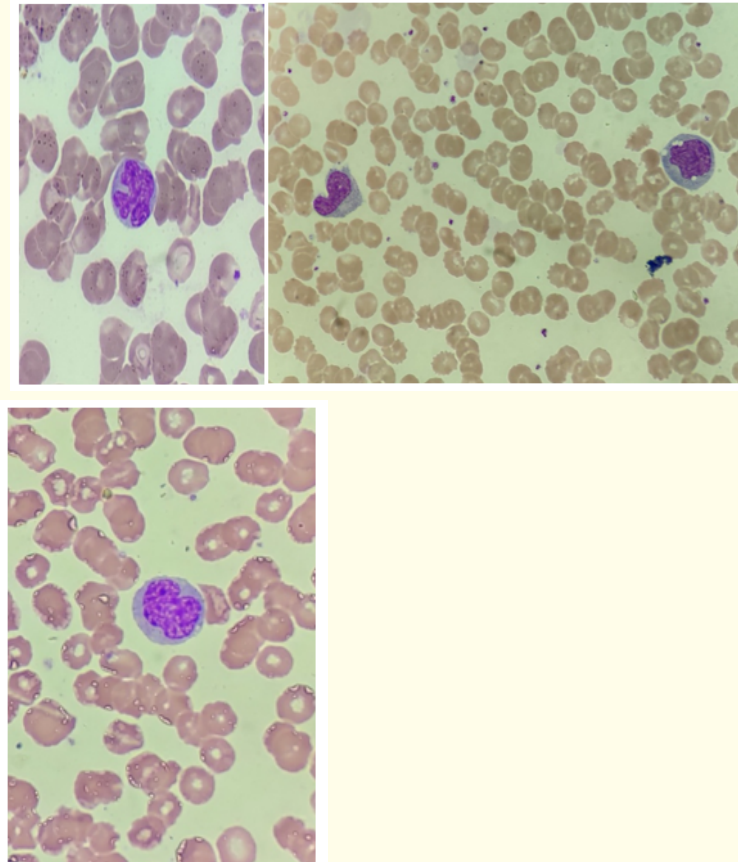

Figure 3: Covicytes with nucleomegaly, irregular nuclear contours and basophilic cytoplasm.

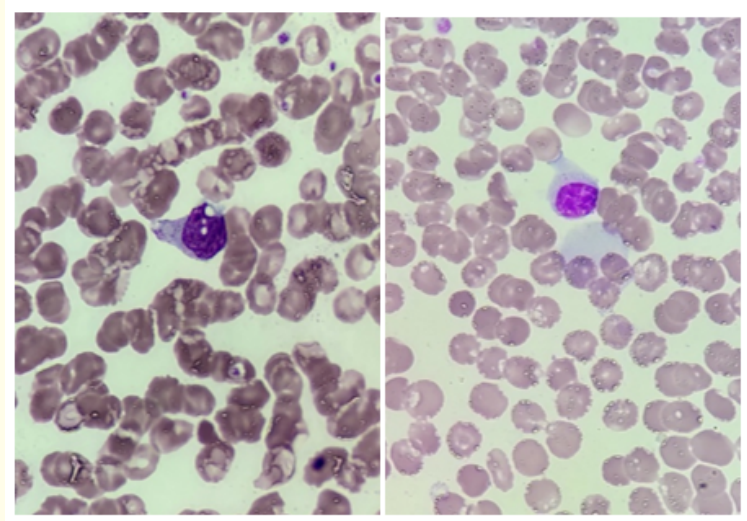

Figure 4: Covicytes with nucleomegaly, nuclear indentation, coarsely granular chromatin and flowy, granular cytoplasm.

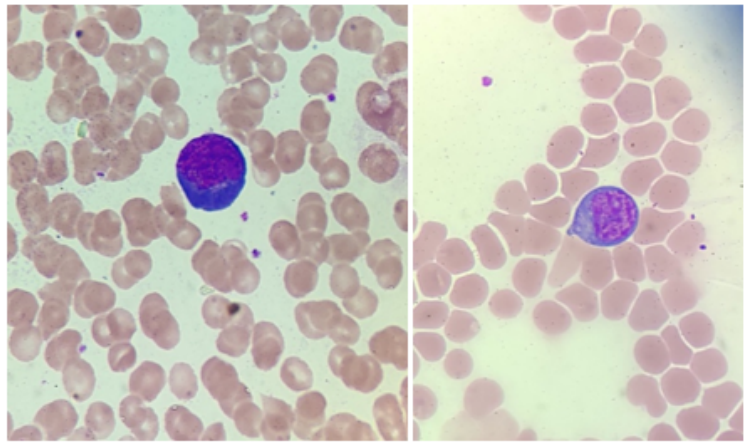

Figure 5: Covicytes with plasmacytoid morphology.

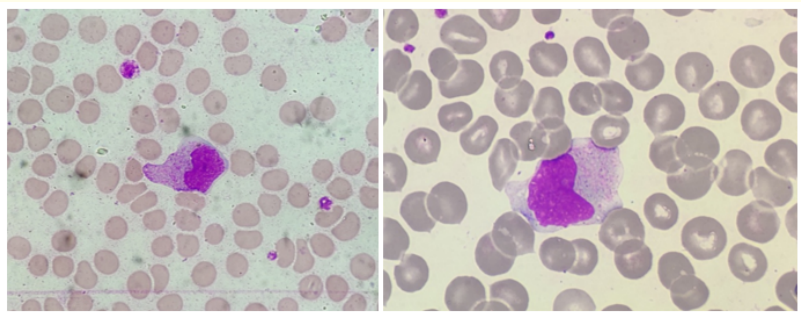

Figure 6: Large granular lymphocytes.

\section{Discussion and Conclusion}

We are currently facing the largest global health emergency in the decades in the form of devastating outbreak of Covid-19. With 

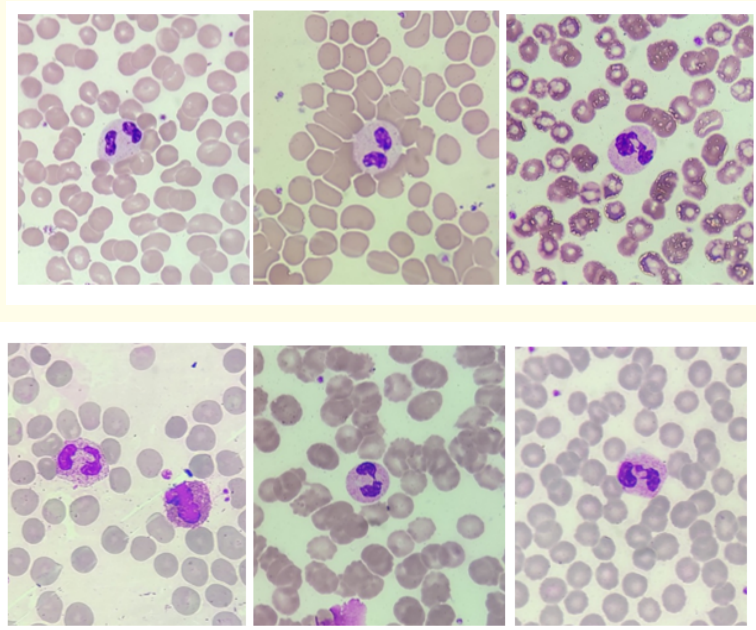

Figure 7: Morphological appearance of the Neutrophils exhibiting Acquired Pseudo Pelger-Huet Anomaly on Peripheral Blood Smear with Leishman stain under 1000x magnification.

the pandemic proceeding unabated, it will be very critical to determine the exposed and/or infected people, especially those with asymptomatic or very mild forms of the disease who are overlooked source of viral shedding and likely to act inadvertently as the major transmitters of the disease. It is already brought out in various other studies previously that the viral loads are inversely correlated with disease severity and that greater viral loads are seen in mild Covid-19 disease (1). In this study we used a systematic approach to study individuals who are asymptomatic or with mild to moderate disease at the very early stages of the disease in terms of their haematological, biochemical and minimal serological parameters so as to assess the evolution of the disease affecting these parameters.

We chose to study the haematological indices and biochemical parameters as they are the common laboratory investigations performed on patients admitted to the hospitals with fever and also these are readily available in resource constraint milieu such as this peripheral mid-zonal hospital location. Blood counts often provide clues regarding the diagnosis and complications of infectious disease, guiding the clinicians to arrive at suitable diagnosis and formulating treatment protocols. There is limited literature on the study of peripheral smear findings in Covid-19. One such study reveals the presence of APHA, prominent abnormal granulation, left shift in granulocytes, abnormal platelet morphology, apoptotic cells and reactive lymphocytes [26]. Pelger Huet anomaly is a benign hereditary condition resulting from mutations in the Laminin B receptor (LBR) and is characterized by the presence of hyposegmented neutrophils with dense chromatin. There are acquired causes of this anomaly and these include Myelodysplastic Syndrome, infections such as tuberculosis, HIV/AIDS, Influenza A, infectious mononucleosis, Parvovirus and drugs like immune-suppressive agents and antibiotics [27]. The APHA is not reported to be associated with SARS-CoV infection.

Currently, the Real Time RT-PCR assay is the gold standard method in the detection of SARS-CoV-2. However, with sensitivity of RT-PCR in the diagnosis of Covid-19 is only $60-70 \%$, a significant number of false negative cases have been reported which could have been due to problems with sample collection and transportation, RNA extraction, presence of enzyme inhibitors and the RTPCR method per se. The accuracy of viral RNA swabs also depends on the site and quality of sampling. It is postulated that the sensitivity of RT-PCR is around 93\% for broncho-alveolar lavage, 72\% for sputum, $63 \%$ for nasal swabs and only $32 \%$ for throat swabs. The accuracy also depends on the stage of the disease and the degree of viral replication or clearance [21-23]. Gene targets being employed also affect the sensitivity of the test and higher sensitivities are achieved when multiple genes are used in combination $[24,25]$. Several studies on coronaviruses testing have estimated that RT-PCR diagnostic tests yield a rate of $41 \%$ false negatives [2-4]. False-negatives carrivaly substantial risks of spreading the infection in the community. In hospital, such patients may even be transferred inadvertently into non-covid-19 wards leading to the spread of hospital acquired Covid-19 infection amongst the other in-patients and health care workers who in turn risk spreading to other vulnerable individuals [16]. In such instances, haematological assessment with proper interpretation of peripheral blood evaluation can guide the clinicians in the presumptive diagnosis of such missed cases and application of appropriate Infection Prevention and Control measures for the containment of further spread of the infection and design of institutional protocols.

We have also brought out in the study that much of the patients who were initially asymptomatic particularly those tested as part of the contact tracing, later developed mild to moderate symptoms in the form of fever, running nose, sore-throat, cough and a mild drop in the peripheral blood oxygen saturation. So the proportion of asymptomatic patients in our study population was relatively low compared to that revealed as $40-45 \%$ by various other studies $[6,7]$. However, such asymptomatic carriers, to whatever degrees 
their numbers might be, serve as 'silent spreaders' who warrant attention as part of disease prevention and control. These relatively low numbers of asymptomatic carriers did not show apparent Covid-19 related changes in any of the biochemical or hematological parameters including on the peripheral blood smear study. Similar findings were revealed in previous studies which revealed that the asymptomatic carriers had a longer duration of viral shedding than the symptomatic Covid-19 patients, further highlighting the importance of contact tracing and disease surveillance [8].

It is amply clear from our study that the majority of Covid-19 patients initially present with Relative Lymphocytosis. The definition of relative Lymphocytosis is an increase in the differential count of white blood cell of more than $40 \%$ in the presence of normal absolute white cell count. Studies have revealed that the initial increase in lymphocytes in peripheral blood in Acute Covid-19 is due to the activation of T-lymphocytes in response to SARS-CoV-2 virus [5]. Most asymptomatic patients, probably due to robust Tcell immunity, clear the virus with minimal or no symptomatology. However, those with mild to moderate disease, exhibit initial Relative Lymphocytosis similar to the asymptomatic patients but later there is development of lymphopenia and in a few instances leukocytopenia as well.

The peripheral blood smear too showed similar findings with increase in the number and pleomorphism of activated T-lymphocytes, Covicytes and Acquired Pelger Huet Anomaly (APHA) in the neutrophils as the disease progressed with increase in clinical severity and worsening of symptomatology to a point where there occurs an increase in the proportion of neutrophils leading to an increase in the Neutrophil to Lymphocyte ratio. With recovery, covicytes gradually decrease in number but there is persistence of occasional covicytes which were observed in most patients who were assessed hematologically prior to discharge after being declared Covid-19 by RT-PCR testing. While the proportion of covicytes reduced as the patients recovered with improvement in symptomatology and waning viral loads, the Acquired Pseudo Pelger Huet anomaly in the neutrophils persisted for protracted periods of time and was appreciated in peripheral blood smear examination carried out when these Covid-19 recovered patients returned for blood evaluation for some other ailment weeks later. The presence of activated lymphocytes in the peripheral blood smear is the hallmark of some infections such as infectious mononucleosis, Bordetella pertussis, hanta virus and varying numbers of these can also be seen autoimmune disorders and malignancies $(28,29,30)$. Our study showed a spectrum of activated lymphocytes in the peripheral blood and has been described as Covicytes.
The above follows the covicytes are ephemeral while the APHA in neutrophils are more enduring and persist for a relatively longer duration of time. The corollary is that the presence of covicytes along with APHA in neutrophils can serve as a surrogate marker of SARS-CoV-2 infection permitting a presumptive diagnosis of Covid-19. The findings also allow isolation of such suspect patients for further confirmation by RT-PCR or any other diagnostic test thereby precluding the spread of infection. The above method also provides an alternative cheap and reliable Infection Prevention and Control mechanism in hospital settings for detecting Covid-19 cases amongst in-patients who were missed either during clinical assessment, if done cursorily or as RT-PCR false-negative cases. It will also enable efficient contact tracing, in the event of such patients being confirmed as Covid-19.

Correlation between Covicytes, APHA and inflammation associated markers such as CRP, LDH and Neutrophil to Lymphocyte Ratio (NLR) were also drawn. We analysed that there is a linear correlation between lymphocyte decline, raised NLR, heightened inflammation markers and severity of infection.

This study enrolled individuals of an organisation who are generally considered physically fit and hence the study population did not suffer from any significant co-morbidities which could otherwise have deleterious effect on the course of the disease, as seen in the general population wherein people with co-morbidities like obesity, hypertension, cardiovascular disease, Diabetes mellitus, Chronic obstructive pulmonary disorder and others which adversely affect the outcome. Hence, the sample comprised of physically robust individuals weeding out all the confounding variables which could affect the natural course of the disease.

\section{Ethical Approval}

Informed consent was obtained from the patients for publication of this paper and accompanying images.

\section{Declaration of Interests}

The authors declare that they have no known competing financial interests or personal relationship that could have appeared to influence the work reported in this paper.

Morphological findings in Peripheral blood Smear in Covid-19 patients admitted in the isolation facility of this hospital between June 2020 and Oct 2020.

Varied morphological appearance of the Activated lymphocytes on Peripheral Blood Smear with Leishman stain under 1000x magnification. 
Study on the Effects of Sars-Cov-2 Infection on the Hematological and Biochemical Parameters and Clinicopathological Correlation in the Evolution of Covid-19

\section{Bibliography}

1. Kimon V Argyropoulos., et al. "Association of initial viral load in SARS-CoV-2 patients with outcome and symptoms". The American Journal of Pathology 190.9 (2020): 1881-1887.

2. Wang C., et al. "A novel coronavirus outbreak of global health concern". Lancet 395 (2020): 470-473.

3. Wikramaratna P., et al. "Estimating false negative detection rate of SARS-CoV-2 by RT-PCR". Euro Surveillance 25.50 (2020): 2000568.

4. Li D., et al. "False negative results of Real-Time Reverse Transcriptase Polymerase Chain Reaction for Severe Acute respiratory Syndrome Coronavirus 2: Role of Deep learning based CT diagnosis and Insights from two cases". Korean Journal of Radiology (2020): 505-508.

5. TakayuSekine., et al. "Robust T cell immunity in convalescent individuals with asymptomatic or mild Covid-19". Cell 183.1 (2020): 158-168.e14.

6. Qiu J. "Covert coronavirus infections could be seeding new outbreaks". Nature (2020).

7. Jiao Zhang., et al. "Asymptomatic carriers of Covid-19 as a concern for disease prevention and control". BioScience Trends 14.3 (2020): 206-208.

8. Quan-Xin Long., et al. "Clinical and immunological assessment of asymptomatic SARS-CoV-2 infections". Nature Medicine (2020).

9. Hoffmann M., et al. "SARS-CoV-2 cell entry depends on ACE2 and TMPRSS2 and is blocked by clinically protease inhibitor". Cell 181 (2020): 271-280.

10. LU R., et al. "Genomic characterization and epidemiology of 2019 novel coronavirus: implications for virus origins and receptor binding". Lancet 395 (2020): 565-574.

11. Zhu N., et al. "A novel Coronavirus from patients with pneumonia in China, 2019". The New England Journal of Medicine 382 (2020): 727-733.

12. Chinazzi M., et al. "The effect of travel restrictions on the spread of the 2019 novel coronavirus (Covid-19) outbreak". Science 368 (2020): 395-400.

13. Zhang T., et al. "Probable pangolin origin of SARS-CoV-2 associated with Covid-19 outbreak". Current Biology 30 (2020): 1946-1351.
14. Hamming I., et al. "Tissue distribution of ACE2 protein, the functional receptor for SARS coronavirus. A first step in understanding SARS pathogenesis". The Journal Pathology 203.2 (2004): 631-637.

15. Wang Y., et al. "Combination of RT-qPCR testing and clinical features for diagnosis of Covid-19 facilitates management of SARS-CoV-2 outbreak". Journal of Medical Virology 92.6 (2020): 538-539.

16. Nacoti M., et al. "At the epicentre of the Covid-19 pandemic and humanitarian crises in Italy: changing perspectives on preparation and mitigation". (2020).

17. Huang C., et al. "Clinical features of patient infected with 2019 novel coronavirus in Wuhan, China". Lancet 395.10223 (2020): 497-506.

18. Chen N., et al. "Epidemiological and clinical characteristics of 99 cases of 2019 novel coronavirus pneumonia I Wuhan, China: a descriptive study". Lancet 395.10223 (2020): 507-513.

19. Wang D., et al. "Clinical characteristics of 138 Hospitalized patients with 2019 Novel coronavirus-infected pneumonia in Wuhan, China”. JAMA 323.11 (2020): 1061-1069.

20. Wu C., et al. "Risk factors associated with Acute Respiratory Distress Syndrome and Death in patients with Coronavirus disease 2019 Pneumonia in Wuhan, China". JAMA Internal Medicine 80.7 (2020): 934-943.

21. Wang W., et al. "Detection of SARS-CoV-2 in different types of clinical specimens". JAMA 323.18 (2020): 1843-1844.

22. Sethuram N., et al. "Interpreting diagnostic tests for SARSCoV-2". JAMA 323.22 (2020): 2249-2251.

23. Wolfel R., et al. "Virological assessment of hospitalized patients with Covid-19”. Nature 581 (2020): 465-469.

24. Vogels CBF., et al. "Analytical sensitivity and efficiency comparisons of SARS-CoV-2 qRT-PCR assays". medRxiv (2020).

25. Chan JF., et al. "Improved molecular diagnosis of Covid-19 by the novel, highly sensitive and specific Covid-19 RdRp/Hel real time Reverse Transcription Polymerase Chain Reaction assay validated in vitro and with clinical specimens". Journal of Clinical Microbiology 58.5 (2020): e00310-320.

26. Zini G., et al. "Morphological anomalies of circulating blood cells in Covid-19". American Journal of Hematology 95.7 (2020): 870-872. 
Study on the Effects of Sars-Cov-2 Infection on the Hematological and Biochemical Parameters and Clinicopathological Correlation in the Evolution of Covid-19

27. Dusse LM., et al. "Acquired Pelger-Huet: what does it really mean?" ClinChimActa 411 (2011): 1587-1590.

28. George TI. "Malignant or benign leucocytosis". Hematology ASH Education Program 2012 (2012): 475-484.

29. Klein E., et al. "Epstein-Barr virus infection in humans: from harmless to life endangering virus-lymphocyte interactions". Oncogene 26.9 (2007): 1297-1305.

30. Koster F., et al. "Rapid presumptive diagnosis of hantavirus cardiopulmonary syndrome by peripheral blood smear review". American Journal of Clinical Pathology 116 (2001): 665-672.

Volume 5 Issue 10 October 2021

(C) All rights are reserved by Rakesh Holla A., et al. 